\title{
Photodynamic antimicrobial chemotherapy for Staphylococcus aureus and multidrug-resistant bacterial burn infection in vitro and in vivo
}

This article was published in the following Dove Press journal:

International Journal of Nanomedicine

17 August 2017

Number of times this article has been viewed

\author{
Bingjie Mai ${ }^{1,2}$ \\ Yiru Gao ${ }^{1,2}$ \\ Min $\mathrm{Li}^{1,2}$ \\ Xiaobing Wang ${ }^{1,2}$ \\ Kun Zhang ${ }^{1,2}$ \\ Quanhong Liu' ${ }^{1,2}$ \\ Chuanshan $\mathrm{Xu}^{3}$ \\ Pan Wang ${ }^{1,2}$
}

'Key Laboratory of Medicinal Resources and Natural Pharmaceutical Chemistry, Ministry of Education, ${ }^{2}$ National Engineering Laboratory for Resource Development of Endangered Crude Drugs in Northwest China, College of Life Sciences, Shaanxi Normal University, Xi'an, ${ }^{3}$ School of Chinese Medicine, Faculty of Medicine, Chinese University of Hong Kong, Hong Kong, China
Correspondence: Pan Wang;

Chuanshan Xu

College of Life Sciences, Shaanxi

Normal University, Xi'an/School of

Chinese Medicine, Faculty of Medicine,

Chinese University of Hong Kong,

Hong Kong, China

Tel +86298531 0275

Email wangpan@snnu.edu.cn; xcshan@।63.com
Background and objectives: Antibiotic resistance has emerged as one of the most important determinants of outcome in patients with serious infections, along with the virulence of the underlying pathogen. Photodynamic antimicrobial chemotherapy (PACT) has been proposed as an alternative approach for the inactivation of bacteria. This study aims to evaluate the antibacterial effect of sinoporphyrin sodium (DVDMS)-mediated PACT on Staphylococcus aureus and multidrug resistant $S$. aureus in vitro and in vivo.

Materials and methods: Bacteria were incubated with DVDMS and exposed to treatment with light. After PACT treatment, colony-forming units were counted to estimate the bactericidal effect. Intracellular reactive oxygen-species production was detected by flow cytometry. Flow cytometry and fluorescence-microscopy detection of bacterial cell-membrane permeability. Enzyme-linked immunosorbent assays were used to determine expression of VEGF, TGF $\beta_{1}$, TNF $\alpha$, IL6, and bFGF factors in burn infection.

Results: DVDMS-PACT effectively killed bacterial proliferation. Intracellular ROS levels were enhanced obviously in the PACT-treatment group. SYTO 9 and propidium iodide staining showed a decrease in the ratio of green:red fluorescence intensity in the PACT-treatment group in comparison to the control group. Enzyme-linked immunosorbent-assay results revealed that in the healing process, the expression of $\mathrm{bFGF}, \mathrm{TGF} \beta_{1}$, and VEGF in the treatment group were higher than in the control group, which inhibited inflammation-factor secretion. In addition, skin-tissue bacteria were reduced after treatment.

Conclusion: These results indicate that DVDMS-PACT presents significant bactericidal activity and promotes wound healing after burn infections.

Keywords: PACT, antibacterial efficacy, burn infection, MDR

\section{Introduction}

Burns are a global public health problem, especially in undeveloped countries that lack adequate medical facilities, in terms of morbidity, long-term disability, and mortality. ${ }^{1,2}$ Wound infection is one of the most common complications after severe trauma, burn, or surgery, and it prolongs hospitalization, causes significant morbidity, and expends a considerable amount of medical resources. A previous study reported that a reduction in overall wound-infection rate from $4.42 \%$ to $2.5 \%$ at a single medical center over a 10-year period saved approximately $\$ 3$ million in hospital costs. ${ }^{3-5}$ Exposure to hot water is one of the most frequent causes of burns. ${ }^{6}$ All wounds will have some bacterial colonization. Staphylococcus aureus bacteria are early colonizers, and account for the majority of burn-wound infections; moreover, they are responsible for many other skin and soft-tissue infections in humans, including impetigo, folliculitis, cellulitis, and 
infected ulcers..$^{7-9}$ More concerning is the fact that $S$. aureus skin infection can progress to invasive and life-threatening infections, such as bacteremia, abscesses, pneumonia, and sepsis. ${ }^{10,11}$ Several therapeutic strategies are used to combat infection by $S$. aureus, including antibiotic-based treatment, antibiotic-free treatments, immunotherapy, therapeutic vaccines, and occasionally combinations of these options. ${ }^{12}$

The widespread use of antibiotics has resulted in a growing problem of antimicrobial resistance in community and hospital settings. Antimicrobial classes for which resistance have become a worrisome problem include the $\beta$-lactams, the glycopeptides, and the fluoroquinolones. ${ }^{13}$ Therefore, novel antimicrobial drugs are continuously needed to counteract bacterial resistance development. ${ }^{14}$ To keep up the pace of antibiotic resistance, new antibiotics, including vancomycin, linezolid, tedizolid, daptomycin, ceftaroline, and tigecycline, have been developed and introduced in recent years. ${ }^{15,16}$ However, the outbreak of various multidrug-resistant (MDR) S. aureus strains globally at an alarming rate resulted in treatment difficulties, which have imposed a burden on healthcare systems and simultaneously intensified the need for new antimicrobial agents. ${ }^{17}$ In particular, the use of topical antibiotics is controversial, since it has been suggested that such an approach induces antibiotic resistance faster than the use of oral antibiotics. ${ }^{18,19}$

It has been reported that silver nanoparticles are strong bactericidal agents, but they are also cytotoxic. Embedding them in a polymer matrix may reduce their cytotoxicity. ${ }^{20}$ Antimicrobial nanomaterials are also available nanoporous bioglass containing silver (Z-)-4-bromo-5-(bromomethylene)2(5H)-furanone-loaded poly(L-lactic acid) nanoparticles on microarc-oxidized titanium. These materials have good antibacterial efficiency. ${ }^{21-24}$ Photodynamic antimicrobial chemotherapy (PACT) is a promising method to eradicate pathogenic bacteria, because it kills these via cytotoxic reactive oxygen species (ROS). ROS are produced by the photosensitive drug after light irradiation, and inflict aspecific damage to bacteria. ${ }^{25,26}$ Much is already known about the photodynamic inactivation of microorganisms: both antibiotic-sensitive and -resistant strains can be successfully photoinactivated, and there is the additional advantage that repeated photosensitization of bacterial cells does not induce a selection of resistant strains. ${ }^{27-30}$

In our previous study, we investigated the photodynamic activity of a new photosensitive (sinoporphyrin sodium [DVDMS]). We observed that light-activated DVDMS enhanced intracellular ROS levels, which significantly induced cell death and markedly damaged S. aureus. ${ }^{31}$ In this

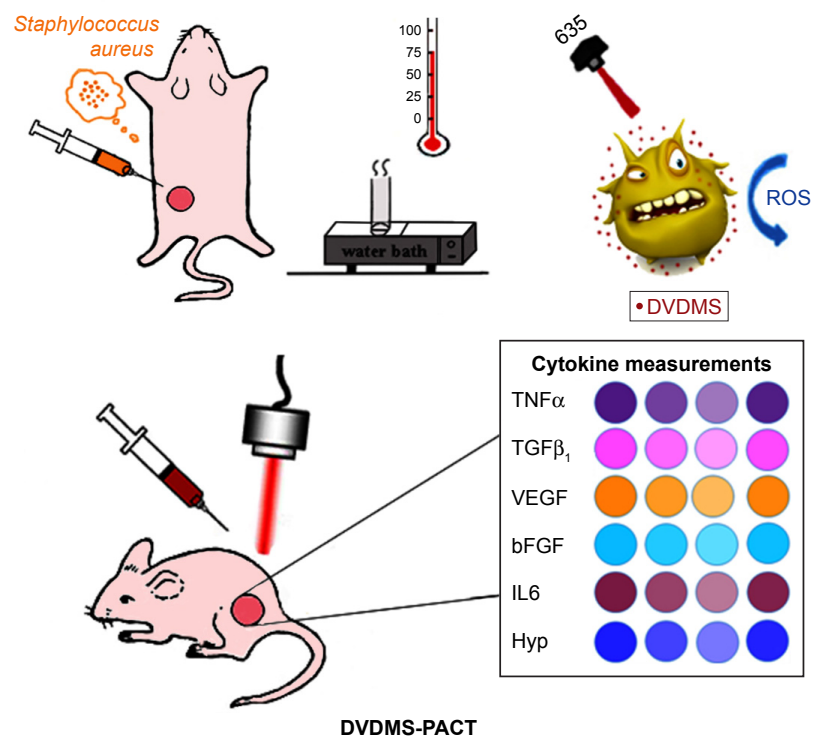

Figure I Diagram of in vivo DVDMS-PACT treatment protocol.

Notes: Burn-infected mice were randomly divided into four groups (eight wounds per group): model, $2 \mu \mathrm{M}$ PACT, $5 \mu \mathrm{M}$ PACT, and $10 \mu \mathrm{M}$ PACT. The model mice did not receive any treatment. The laser was utilized with a power intensity of $300 \mathrm{~mW} / \mathrm{cm}^{2}$. Finally, concentrations of TNF $\alpha, T G F \beta_{\text {I }}$ VEGF, bFGF, IL6, and Hyp were detected using ELISA at different time points.

Abbreviations: DVDMS, sinoporphyrin sodium; ELISA, enzyme-linked immunosorbent assay; Hyp, hydroxyproline; PACT, photodynamic antimicrobial chemotherapy; ROS, reactive oxygen species.

study we investigated in vivo PACT of second-degree thermal burn wounds in mice with $S$. aureus and MDR S. aureus infections (Figure 1). We hypothesized that PACT could significantly downregulate inflammation of the infected tissues in the burns. The possible mechanism of action and clinical application were also investigated.

\section{Materials and methods Bacterial growth}

S. aureus (CMCC 26003) and MDR S. aureus (ATCC 29213) were provided by the Shaanxi Provincial Institute of Microbiology (Xi'an, China). The strains were stored at $-80^{\circ} \mathrm{C}$ as glycerol stocks. For experiments, cultures of S. aureus were grown on trypticase soy agar (TSA; Aobox Biotechnology, Beijing, China) for 24 hours. A colony was subcultured on tryptic soy broth (Aobox Biotechnology) at $37^{\circ} \mathrm{C}$ overnight on a shaker incubator at $200 \mathrm{rpm}$ (TS-200B; Tensuc Laboratory Instrument Manufacturing, Shanghai, China), then centrifuged for 5 minutes at $8,000 \mathrm{rpm}$ and diluted with sterile $0.85 \%$ saline ( $\mathrm{pH} 7.5$ ) to a concentration of $10^{8} \mathrm{CFU} / \mathrm{mL}$.

\section{Sensitizers and irradiation}

DVDMS was kindly provided by Professor Qicheng Fang from the Chinese Academy of Medical Sciences (Beijing, 
China). It has a purity of $98.5 \%$. It was dissolved in sterile physiological saline solutions to a final storage concentration of $1 \mathrm{mM}$ and stored in the dark at $-20^{\circ} \mathrm{C}$. A semiconductor laser (excitation wavelength $635 \mathrm{~nm}$; Ningju Photoelectric Technology, Xi'an, China) was used for PACT. Laser irradiance was measured using a radiometry system (Ningju Photoelectric Technology).

\section{Reagents}

$2^{\prime}, 7^{\prime}$-Dichlorodihydrofluorescein diacetate $\left(\mathrm{H}_{2}-\mathrm{DCF}-\mathrm{DA}\right)$ and SYTO 9 green fluorescent nucleic acid stain were obtained from Thermo Fisher Scientific (Waltham, MA, USA). Propidium iodide (PI) was obtained from the SigmaAldrich (St Louis, MO, USA). Malondialdehyde (MDA) and hydroxyproline (Hyp) assay kits were provided by Jiancheng Bioengineering Institute (Nanjing, China). IL6, bFGF, VEGF, TGF $\beta_{1}$, and TNF $\alpha$ enzyme-linked immunosorbent assay (ELISA) kits were purchased from Calvin Biotechnology (Suzhou, China).

\section{Animals}

Female BALB/c mice (age 5-6 weeks, 18-20 g body weight) were supplied by the Experimental Animal Center of the Fourth Military Medical University (Xi'an, China). They were housed in an air-conditioned room at $23^{\circ} \mathrm{C} \pm 2^{\circ} \mathrm{C}$ with free access to food and water and maintained on a 12-hour light-dark cycle. All experiments using mice were approved by the animal care and use committee of Shaanxi Normal University (Xi'an, China). The mice were anesthetized by pentobarbital sodium (30 mg/kg of body weight) intraperitoneally for surgery and for subsequent PACT. Their back hair was removed using depilatory cream.

\section{Uptake by S. aureus/MDR S. aureus}

To substantiate the enrichment of DVDMS in S. aureus/ MDR $S$. aureus, we examined the uptake of DVDMS by microscopy. Bacteria suspensions and DVDMS were incubated in the dark, and $500 \mu \mathrm{L}$ of each sample was removed at every 15-minute interval. All samples were rinsed twice with PBS and then visualized under fluorescence microscopy (Axio Imager M2; Carl Zeiss Meditec, Jena, Germany).

\section{Photodynamic treatment protocol}

Suspensions of bacteria $\left(10^{8} \mathrm{CFU} / \mathrm{mL}\right)$ were incubated with $2 \mu \mathrm{M}$ or $5 \mu \mathrm{M}$ DVDMS in the dark for 75 minutes at $37^{\circ} \mathrm{C}$, and then added to a 24-well flat-bottom plate. This 24-well plate containing bacterial suspensions was washed once by PBS before illumination, then irradiated with laser light at different light doses $\left(10,30\right.$, and $\left.50 \mathrm{~J} / \mathrm{cm}^{2}\right)$. The temperature was kept at $37^{\circ} \mathrm{C}$ during irradiation.

\section{CFU assay}

CFU assays were used to measure the cytotoxicity of PACT. After photodynamic treatment, bacteria were spread on the TSA in tenfold serial dilutions. After 24-hour incubation at $37^{\circ} \mathrm{C}$, bacteria were counted.

\section{Intracellular reactive oxygen-species production}

$\mathrm{H}_{2}$-DCF-DA, a nonfluorescent cell-permeant compound, is hydrolyzed by endogenous esterases within cells, and the de-esterified product can be converted into the fluorescent compound DCF upon oxidation by intracellular ROS. Fluorescence intensity is proportional to ROS production. Bacteria were coincubated with $10 \mu \mathrm{M} \mathrm{H}_{2}$-DCF-DA and $5 \mu \mathrm{M}$ DVDMS for 75 minutes prior to PACT treatment. After PACT treatment, bacteria were washed with $0.85 \%$ saline, and the fluorescence intensity of DCF in each group was immediately analyzed using flow cytometry (NovoCyte; ACEA Biosciences, San Diego, CA, USA).

\section{Bacteria-viability assay}

The antibacterial activity of DVDMS-PACT was determined after incubation with bacteria suspensions for 75 minutes in the dark at $37^{\circ} \mathrm{C}$. Then, the mixture solutions were exposed to $300 \mathrm{~mW} / \mathrm{cm}^{2}$ light for different periods. Dyes (1:1 ratio) were added to the samples and kept in the dark for 15 minutes. The bacteria stains used were SYTO 9 and PI, which are a green fluorescent nucleic acid stain and a red fluorescent nucleic acid stain, respectively. Stained bacterial cells were visualized under fluorescence microscopy with 488-530 nm dual-band excitation-filter combination for SYTO 9 and PI simultaneously. Meanwhile, fluorescence intensity of the stained bacteria was measured at excitation/emission with fluorescein isothiocyanate for SYTO 9 and tetramethylrhodamine for PI using flow cytometry. The percentage of live cells in each group was represented by dividing the fluorescence intensity at emission 1 by the fluorescence intensity at emission 2.

\section{DNA-fragmentation assay}

DNA damage was evaluated using an easy and quantitative method that is based on flow-cytometry detection of DNA hypoploidy after adding PI to dying cells and permeabilizing them by freeze-thaw cycles. ${ }^{32,33}$ To investigate the effect of DVDMS-PACT on DNA damage to S. aureus, 
oligonucleosomal DNA fragmentation by flow cytometry was performed. Briefly, bacteria were incubated with $5 \mu \mathrm{M}$ DVDMS for 75 minutes in the dark at $37^{\circ} \mathrm{C}$, then irradiated with $50 \mathrm{~J} / \mathrm{cm}^{2}$ of light. After treatment, bacteria were stained with $5 \mu \mathrm{g} / \mathrm{mL}$ PI and freeze-thawed for 30 seconds. Samples were immediately analyzed by flow cytometry.

\section{Model establishment and material processing}

Animal experiments were performed in accordance with the National Institutes of Health's Guide for the Care and Use of Laboratory Animals and approved by the animal care and use committee of Shaanxi Normal University (Xi'an, China). The mice were anesthetized with an intraperitoneal injection of pentobarbital sodium before burn creation. Burn wounds were induced by a tube with $75^{\circ} \mathrm{C}$ contact with the skin. The scald area was $1.5 \mathrm{~cm}$-diameter circle $(1.5 \%-2.2 \%$ of body-surface area calculated according to Meeh's formula). ${ }^{34}$ Tube contact with the skin was for 3, 6, and 9 seconds. After burn administration, the mice were resuscitated with an intraperitoneal injection of $1 \mathrm{~mL}$ sterile saline immediately. After 24 hours, skin-scald areas of different groups were fixed using 10\% formalin for at least 24 hours. Samples were then paraffin-embedded, sectioned, and stained with H\&E. Histopathological changes were observed using light microscopy (E600; Nikon, Tokyo, Japan). Bacteria $\left(100 \mu \mathrm{L}, 10^{9} / \mathrm{mL}\right)$ were injected subcutaneously into the skin after scalding, the wound-infection model was ready after 48 hours, and the next experiment was conducted.

\section{DVDMS-PACT in the burn-infected model}

The burn-infected mice were randomly divided into four groups (eight wounds per group): control, $0.1 \mathrm{~mL} \mathrm{PBS}$; $10 \mu \mathrm{M}$ DVDMS, $50 \mathrm{~J} / \mathrm{cm}^{2}$ light; $5 \mu \mathrm{M}$ DVDMS, $50 \mathrm{~J} / \mathrm{cm}^{2}$ light; and $2 \mu \mathrm{M}$ DVDMS, $50 \mathrm{~J} / \mathrm{cm}^{2}$ light. Injections were administered into the scalded skin, and at 75 minutes postinjection, the mice were exposed to the indicated dose of light. Treatments were repeated the following day.

\section{Tissue homogenates}

The mice were killed at 1, 2, 3, 7, and 14 days after PACT treatment, and skin was excised immediately, rinsed in physiological saline, blotted dry, and weighted. Skin tissue (0.1 g) was homogenized in $1 \mathrm{~mL}$ physiological saline using a tissue grinder, followed by centrifugation at $3,000 \mathrm{rpm}$ at $4^{\circ} \mathrm{C}$ for 10 minutes. Supernatant was prepared for detection. Levels of MDA and Hyp were determined with different kits.

\section{Enzyme-linked immunosorbent assay}

ELISA was performed as described previously. ${ }^{35}$ Briefly, the stop solution changes the color from blue to yellow, and the intensity of the color is measured at $450 \mathrm{~nm}$ using spectrophotometry (SpectraMax M5; Molecular Devices, Sunnyvale, CA, USA). In order to measure the concentration of cytokines in the sample, this ELISA kit includes a set of calibration standards. Calibration standards are assayed at the same time as the samples, and allow the operator to produce a standard curve of optical density versus cytokine concentration. The concentration of cytokines in the samples is then determined by comparing the optical density of the samples to the standard curve.

\section{Wound-tissue Hyp and MDA content determination}

Wound-tissue Hyp and MDA in mice were evaluated by alkaline and colorimetric methods, respectively. Hyp and MDA levels were determined by Hyp and MDA kits.

\section{Bacterial loads in skin}

To determine bacterial counts in the tissue samples, $10 \%$ of the tissue homogenates were then serially diluted in PBS $(1: 10,1: 100,1: 1,000,1: 10,000,1: 100,000,1: 1,000,000)$ and plated on TSA in triplicate. Plates were then incubated for at least 18 hours at $37^{\circ} \mathrm{C}$ under a humidified atmosphere. All colony counts were expressed as $\log _{10} \mathrm{CFU}$ per gram tissue or milliliter wound fluid. Bacterial counts of $>10^{5}$ were considered to indicate bacterial infection.

\section{Wound observation}

To monitor the wound-healing process, we observed the leakage quantity of burn wounds, presence of secretions, healing range, and scabbing at different times after PACT treatment. Pictures were taken at different time points.

\section{Histological assessment}

Major organs were fixed using 10\% formalin for at least 24 hours. Samples were then paraffin-embedded, sectioned, and stained with H\&E. Histopathological changes were observed using light microscopy.

\section{Statistical analysis}

SPSS 19.0 software (SPSS Inc, Chicago, IL, USA) was used for statistical analysis. Values are expressed as means \pm standard deviation of three samples obtained from three independent experiments. Statistical comparisons were made using one-way analysis of variance, and multiple comparisons 
between groups were performed using Tukey's test, with $P<0.05$ considered statistically significant and $P<0.01$ highly significant.

\section{Results}

\section{Uptake of DVDMS in S. aureus/MDR} S. aureus

To substantiate the PACT effect in $S$. aureus/MDR S. aureus, we examined uptake of DVDMS by microscopy. As shown in Figure 2, the vast majority of DVDMS fluorescence can be seen on the cell wall and in the cytoplasm of $S$. aureus after 75 minutes of incubation. Similar DVDMS uptake was also found in MDR S. aureus.

\section{Colony-forming units}

After photodynamic treatment with DVDMS, S. aureus and MDR $S$. aureus CFU was counted. Figure 3 shows significant bacterial activity of $S$. aureus/MDR $S$. aureus. Photodynamic treatment with DVDMS decreased bacteria growth in a DVDMS dose- and light dose-dependent manner. Antibacterial activity on $S$. aureus was observed while DVDMS was incubated at a concentration of $2 \mu \mathrm{M}$, with a 4.2-log reduction in CFU with DVDMS at a concentration of $5 \mu \mathrm{M}$ (Figure 3A). Photodynamic action of DVDMS showed antibacterial activity on MDR $S$. aureus: $3.85-\log$ reduction in CFU at an incubation concentration of $5 \mu \mathrm{M}$ (Figure 3B).

\section{Measurement of reactive oxygen species}

Flow-cytometry analyses indicated that exposure of $S$. aureus/ MDR $S$. aureus to DVDMS-PACT treatment significantly enhanced intracellular ROS levels (Figure 4A and B). Relative ROS production was significantly higher $(P<0.01)$ in the PACT groups than in the control groups in both bacteria, and ROS production was positively related to laser dose. Further, in the PACT groups, $S$. aureus showed considerably higher ROS production than MDR $S$. aureus $(P<0.05)$ (Figure 4C).

\section{Bacteria-viability assay}

Fluorescence intensity was measured by flow cytometry. As Figure 5A and $\mathrm{C}$ shows, there was a decrease in the ratio of green:red fluorescence intensity in the combined-treatment group in comparison with the control group. Furthermore, the fluorescence micrography showed the number of live
A

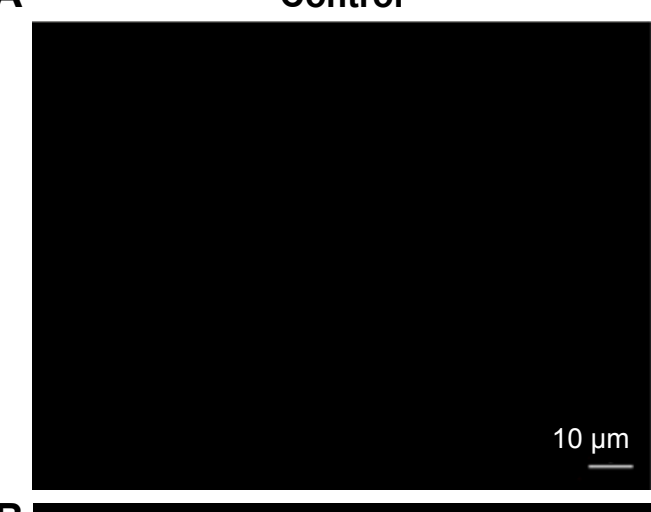

Incubation of 75 minutes
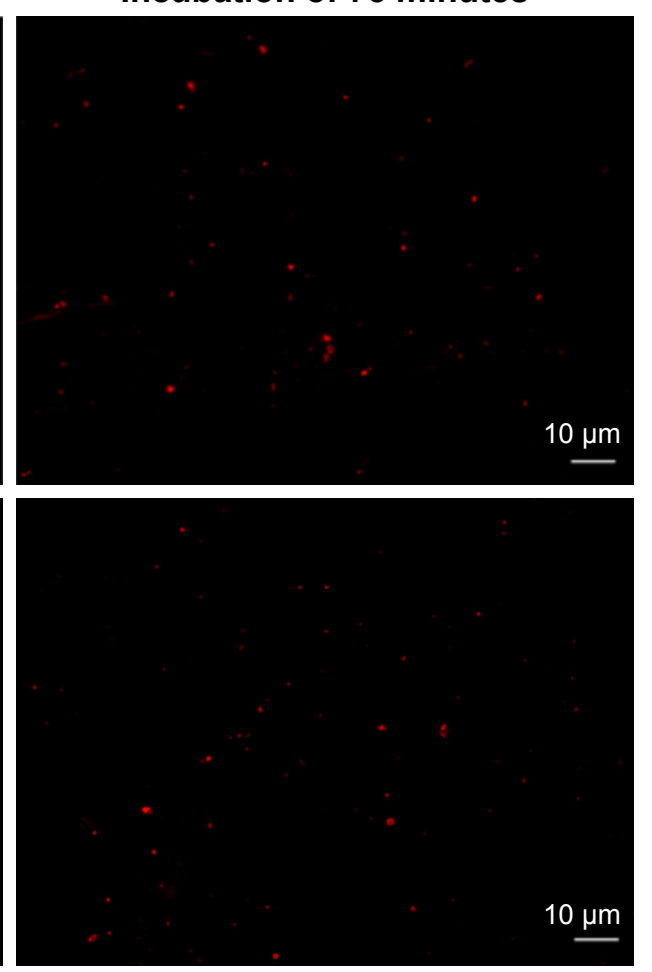

Figure 2 Uptake of DVDMS by Staphylococcus aureus/MDR S. aureus.

Notes: DVDMS uptake in S. aureus/MDR S. aureus. Bacteria were loaded with $5 \mu$ M DVDMS (right panels) and PBS (negative control, left panels) for 75 minutes. (A) S. aureus; (B) MDR S. aureus. The peak was reached at 75 minutes. Magnification is $63 \times$.

Abbreviations: DVDMS, sinoporphyrin sodium; MDR, multidrug-resistant. 
A

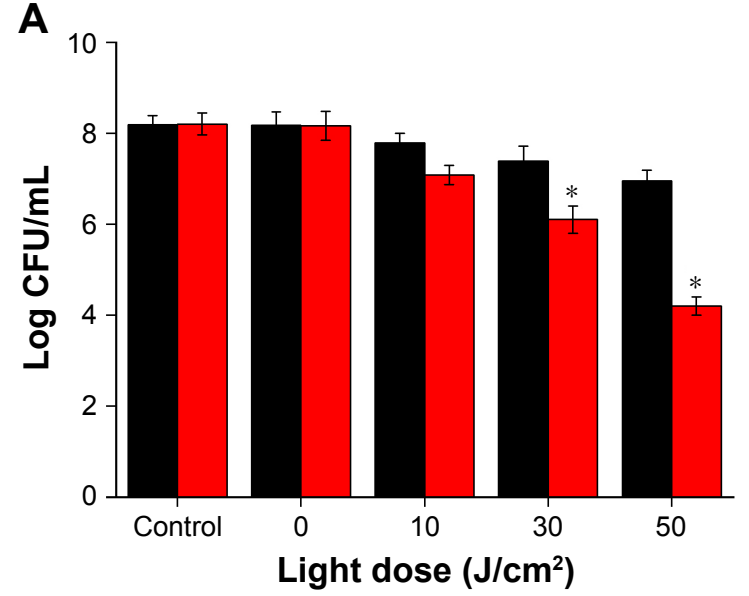

B

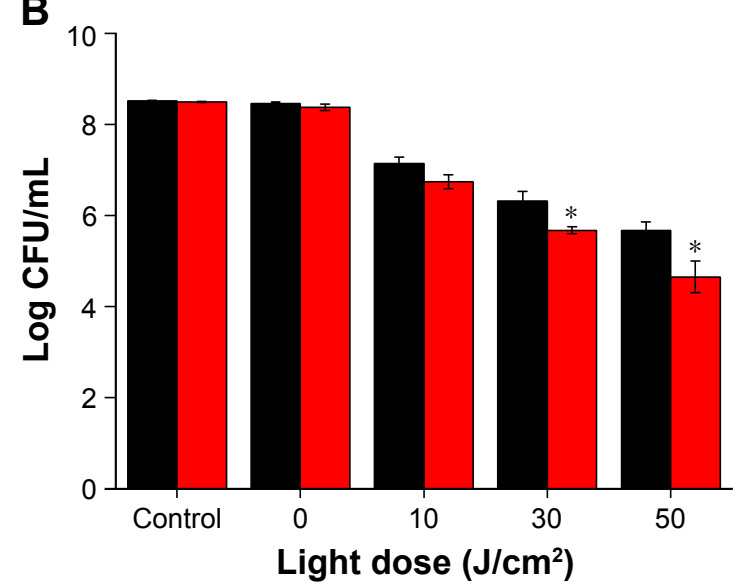

$2 \mu \mathrm{M}=5 \mu \mathrm{M}$

Figure 3 CFU assay of Staphylococcus aureus/MDR S. aureus after DVDMS-PACT treatment.

Notes: Bacterial cells were incubated with $2 \mu \mathrm{M}$ and $5 \mu$ M DVDMS for 75 minutes and irradiated by different light doses. (A) S. aureus: control, negative control; $2 \mu \mathrm{M}, 5 \mu \mathrm{M}$, DVDMS treatment alone; $10 \mathrm{~J} / \mathrm{cm}^{2}, 30 \mathrm{~J} / \mathrm{cm}^{2}, 50 \mathrm{~J} / \mathrm{cm}^{2}$, PACT treatment of $5 \mu$ MVDMS and different light doses. (B) MDR S. aureus: variables as per A. Data expressed as means $\pm S D$ of three experiments. $* P<0.05$ vs control.

Abbreviations: CFU, colony-forming unit; DVDMS, sinoporphyrin sodium; MDR, multidrug-resistant; PACT, photodynamic antimicrobial chemotherapy.

cells (green) decreased, whereas the number of dead (red) cells increased in the combined-treatment group compared with other groups (Figure 5B and D).

\section{DVDMS-PACT-induced DNA}

\section{fragmentation}

We performed PI staining with flow cytometry to evaluate DVDMS-PACT-induced DNA damage in S. aureus/MDR
S. aureus (Figure 6A and B). As shown in Figure 6C, PACT treatment induced a 25.72-fold increase in DNA damage to $S$. aureus, and the damage level increased to 24.15-fold over control for MDR S. aureus.

\section{Enzyme-linked immunosorbent assay}

Using ELISA to detect bFGF and IL6 contents in burn tissues, by day $7 \mathrm{bFGF}$ in the $10 \mu \mathrm{M}$ PACT-treatment group
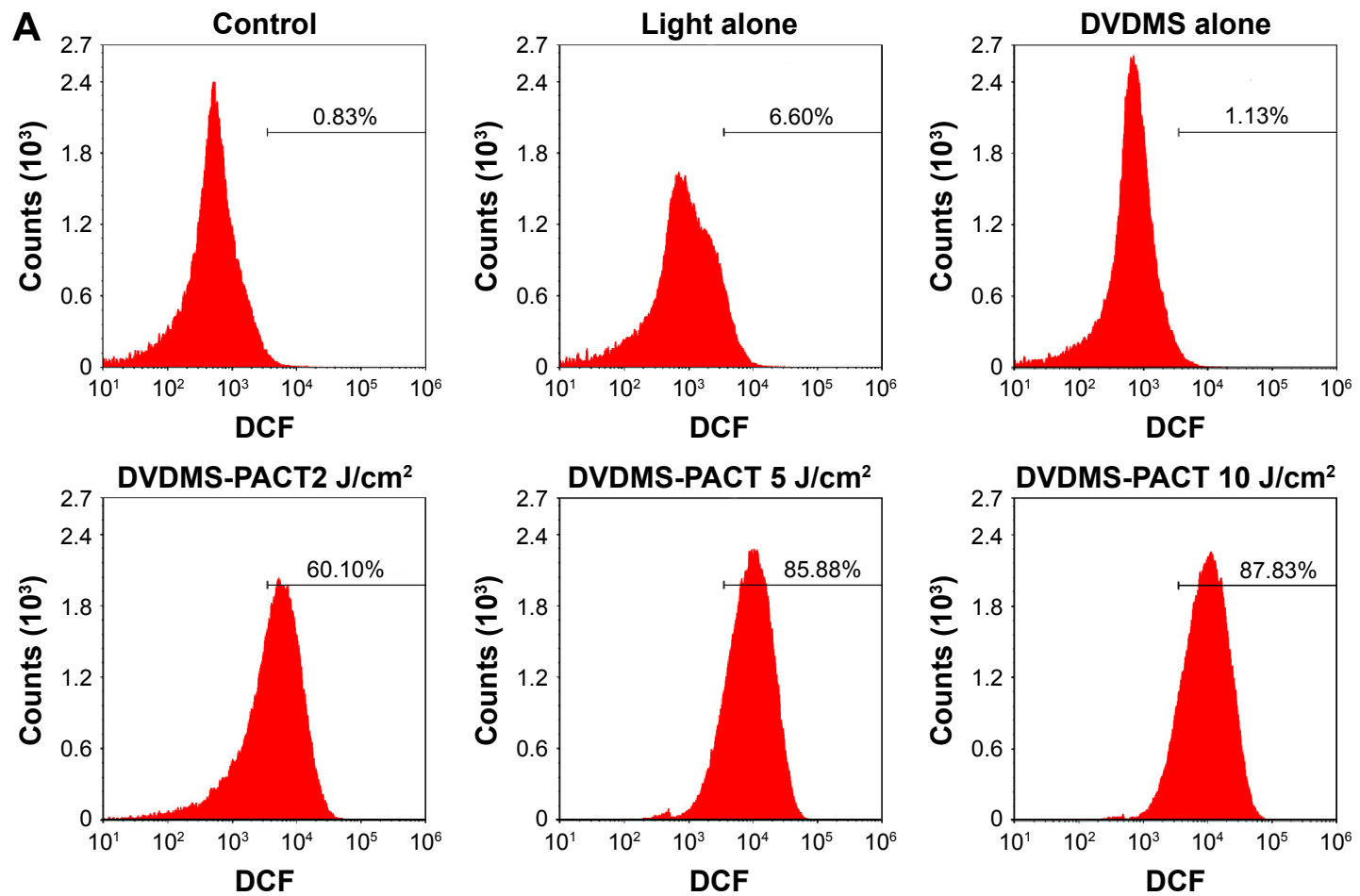

Figure 4 (Continued) 

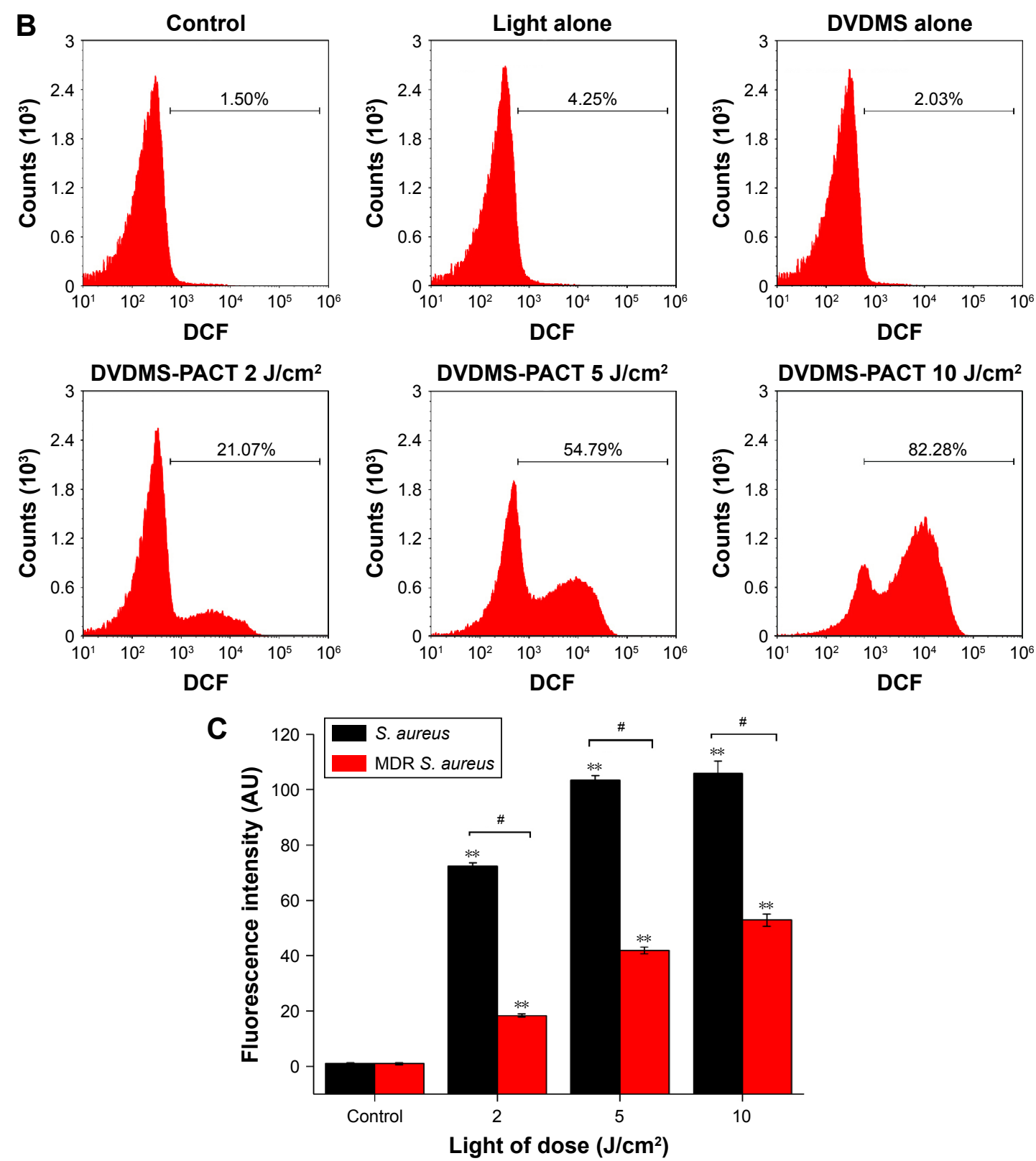

Figure 4 ROS detection by flow cytometry.

Notes: ROS production in Staphylococcus aureus/MDR S. aureus was measured after DVDMS-PACT treatment. Bacteria were preincubated with $\mathrm{H}_{2}-\mathrm{DCF}-\mathrm{DA}$ (I0 $\mu$ M), followed by illumination exposure at different light doses of 10,30 , and $50 \mathrm{~J} / \mathrm{cm}^{2}$ in the presence of DVDMS (5 $\mu$ M). Cytofluorometric profiles represent the distribution of bacterial cells after staining with $\mathrm{H}_{2}$-DCF-DA (S. aureus [A], MDR S. aureus [B]). Control, negative control; light alone, only irradiation 50 J/cm² light dose; DVDMS alone, bacteria treated with $5 \mu$ M DVDMS alone. ${ }^{* * P}<0.01$ vs untreated controls; ${ }^{*} P<0.05$ for $S$. aureus vs MDR $S$. aureus. (C) Distribution of the intensity of DCF + bacteria in different groups.

Abbreviations: DA, diacetate; DCF, dichlorodihydrofluorescein; DVDMS, sinoporphyrin sodium; MDR, multidrug-resistant; PACT, photodynamic antimicrobial chemotherapy; ROS, reactive oxygen species.

had reached its highest level, IL6 had reduced to its minimum level after 3 days (Figure 7A and B). bFGF level was high in the PACT-treatment group, and IL6 in the PACT-treatment group was lower than the control group $(P<0.05)$.

Throughout the healing process, $\mathrm{TNF} \alpha$ expression in PACT-treatment groups was lower than the control group (Figure $7 \mathrm{C}, P<0.01$ ), while at DVDMS concentration of $10 \mu \mathrm{M}, \mathrm{TNF} \alpha$ expression in PACT was significantly lower than the control group. In the late period of treatment, TNF $\alpha$ expression in PACT groups was increasing gradually, but still much lower compared with the control group. Also, in PACT groups lower light doses induced higher TNF $\alpha$ expression. Compared with model group, VEGF content in each treatment group increased gradually with time after burn infection, and levels in each treatment group increased significantly compared with the model group ( $P<0.05$, Figure 7D).

TGF $\beta_{1}$ is an important cell-growth factor that initiates and terminates tissue repair. TGF $\beta_{1}$ expression can promote 
fibroblast growth, capillary angiogenesis, collagen formation, granulation-tissue growth, and wound repair. ${ }^{36}$ The results of this study showed that TGF $\beta_{1}$ expression in PACT groups was better than that in the model control group $(P<0.05)$. The PACT group treated with high light doses was superior to the others $(P<0.05$, Figure $8 \mathrm{~A})$. The high-dose PACTtreatment group significantly increased TGF $\beta_{1}$ content.

\section{Wound-tissue MDA and Hyp content determination}

Hyp content in PACT-treatment groups was obviously higher than the model group after 7, 14, and 21 days treatment
$(P<0.05$, Figure 8B). MDA content in the model group was obviously higher than PACT-treatment groups after 7, 14, and 21 days' treatment $(P<0.05$, Figure $8 C)$.

\section{Bacterial loads in skin}

Antimicrobial activity of DVDMS-PACT against bacteria was evaluated in vivo by homogenizing infected burn wounds and quantifying CFU present in tissue on days 1, 3, 5, 7, and 14. Treatment with DVDMS-PACT significantly decreased the bacterial loads in skin compared with the control group $(P<0.01)$. Figure 9A demonstrates that the density of MDR $S$. aureus bacterial growth decreased gradually in
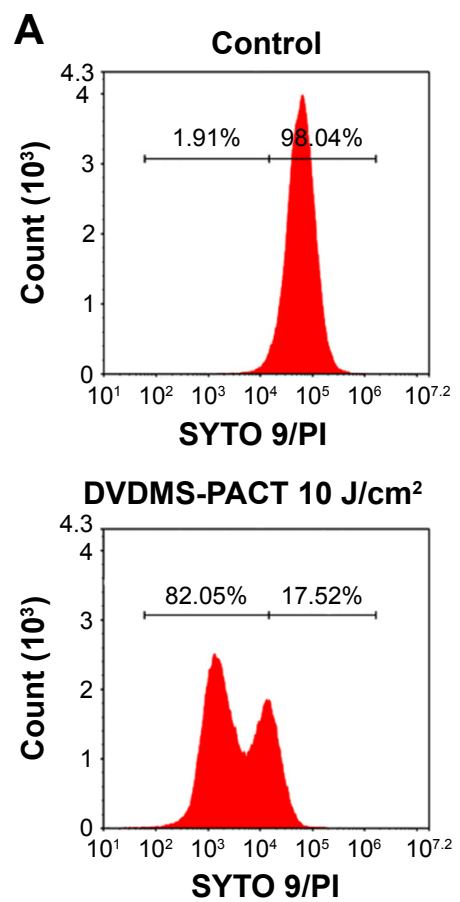

B
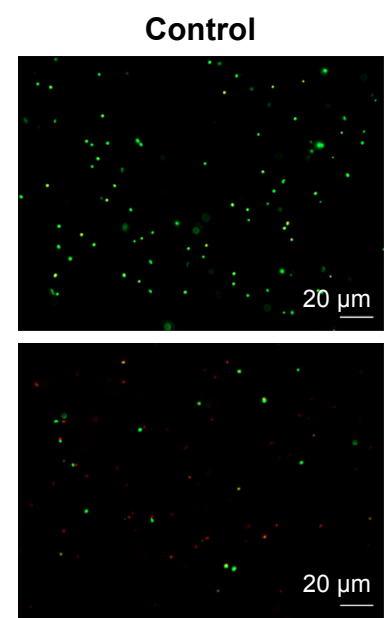

$10 \mathrm{~J} / \mathrm{cm}^{2}$

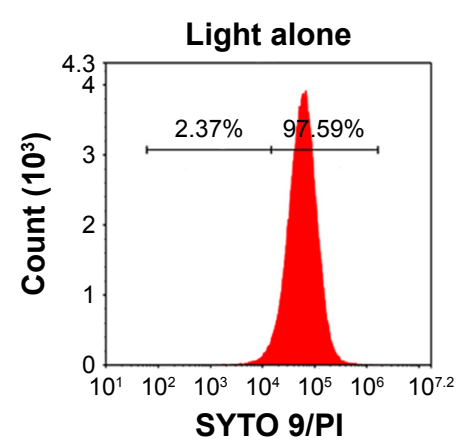

DVDMS-PACT $30 \mathrm{~J} / \mathrm{cm}^{2}$

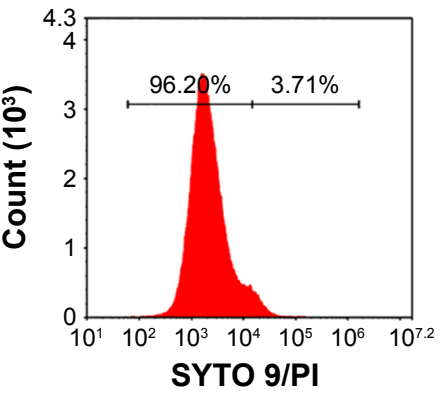

DVDMS alone
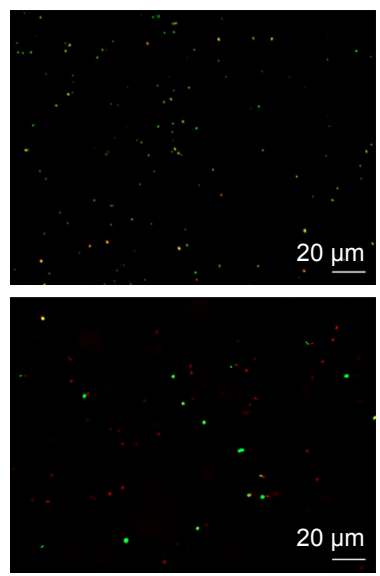

$30 \mathrm{~J} / \mathrm{cm}^{2}$

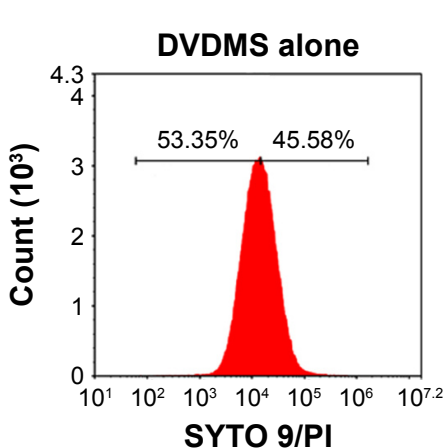

DVDMS-PACT $50 \mathrm{~J} / \mathrm{cm}^{2}$

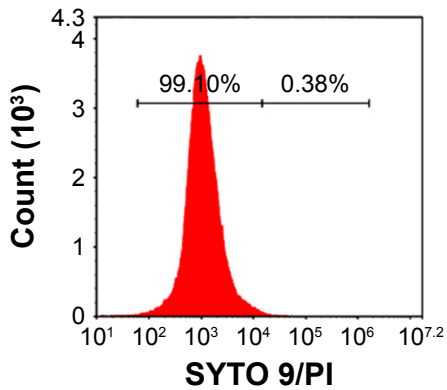

Light alone
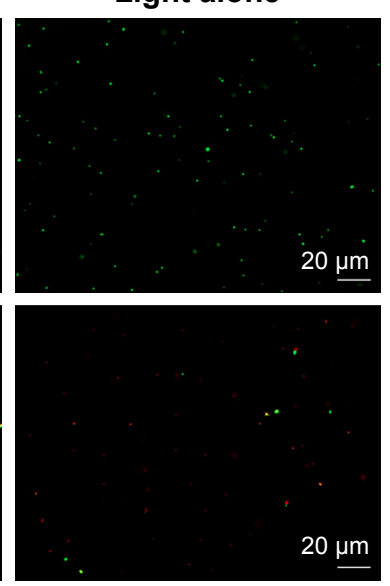

$50 \mathrm{~J} / \mathrm{cm}^{2}$

$5 \mu \mathrm{M}$ DVDMS-PACT

Figure 5 (Continued) 


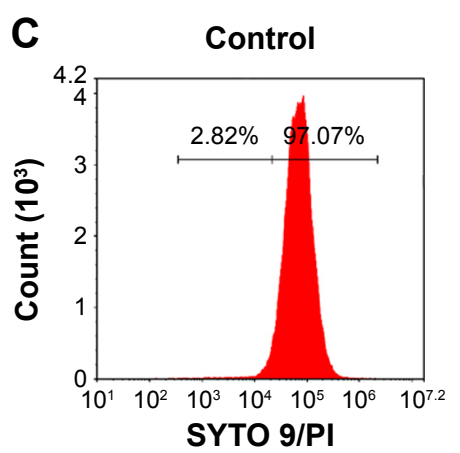

DVDMS-PACT $10 \mathrm{~J} / \mathrm{cm}^{2}$

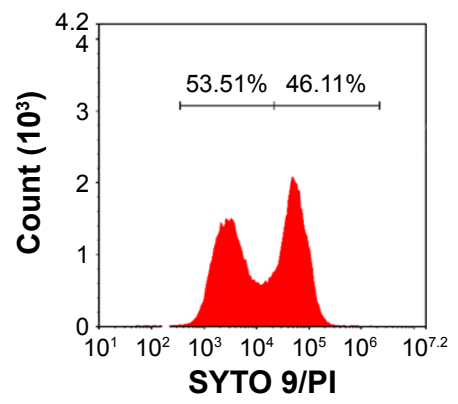

D
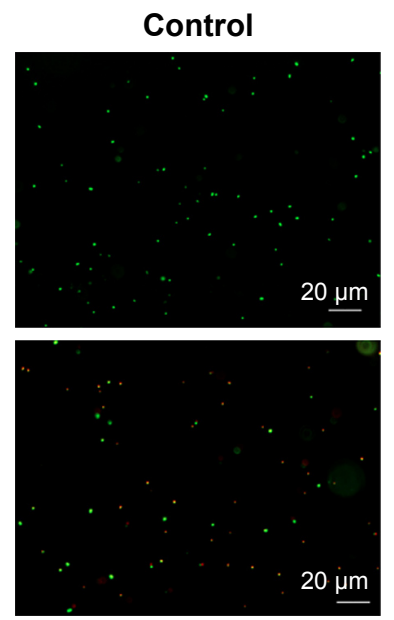

$10 \mathrm{~J} / \mathrm{cm}^{2}$

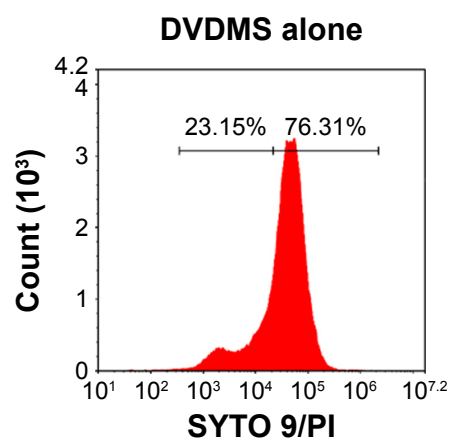

DVDMS-PACT $30 \mathrm{~J} / \mathrm{cm}^{2}$

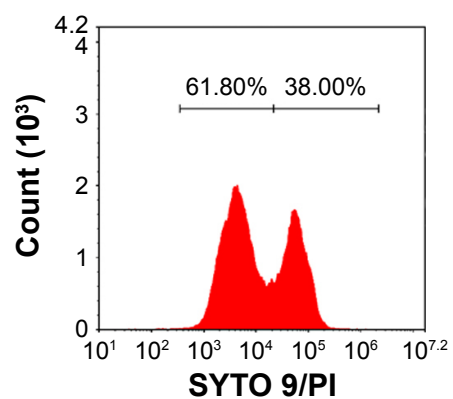

DVDMS alone
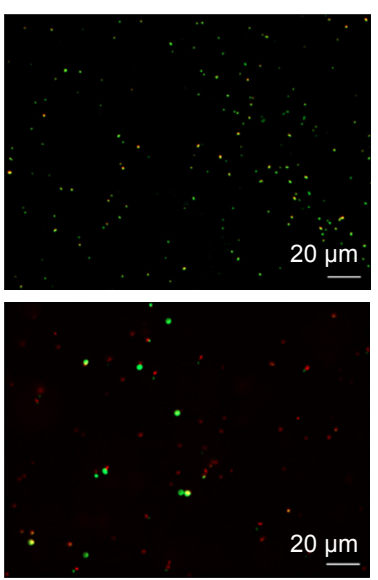

$30 \mathrm{~J} / \mathrm{cm}^{2}$

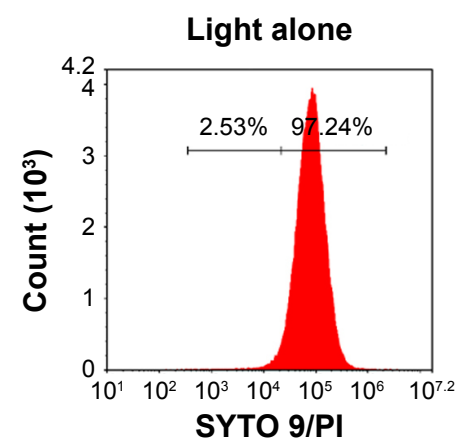

DVDMS-PACT $50 \mathrm{~J} / \mathrm{cm}^{2}$

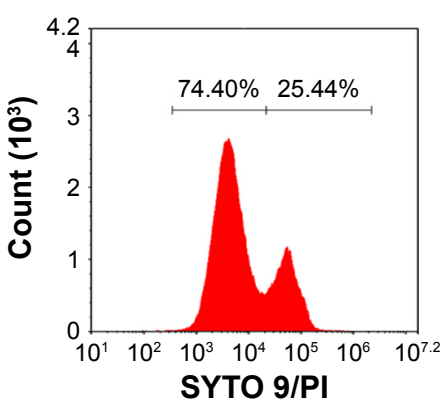

Light alone
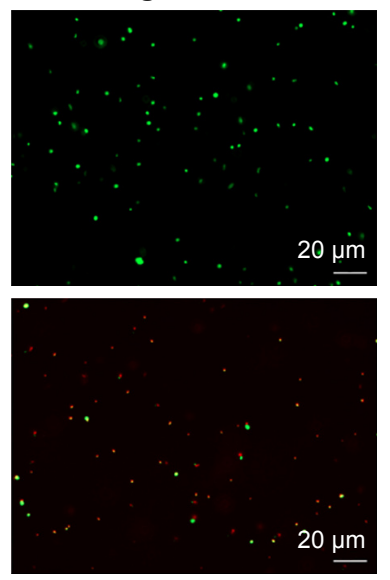

$50 \mathrm{~J} / \mathrm{cm}^{2}$

\section{$5 \mu \mathrm{M}$ DVDMS-PACT}

Figure 5 Flow cytometry and fluorescence microscopy to illustrate bacterial viability.

Notes: (A) Membrane permeability of Staphylococcus aureus was measured using flow cytometry after DVDMS-mediated photodynamic action. Data shown as means \pm SD

(B) Cells were SYTO 9 (green)-PI (red) double-stained and viewed under fluorescence microscopy. (C, D) Same as A and B; bacteria MDR S. aureus. Magnification is 40X. Abbreviations: DVDMS, sinoporphyrin sodium; MDR, multidrug-resistant; PACT, photodynamic antimicrobial chemotherapy; PI, propidium iodide.

the DVDMS-PACT-treatment group. Figure 9B is a quantitative representation of Figure 9A. Figure 9C shows the results for S. aureus.

\section{Wound observation}

Topical treatment with DVDMS-PACT significantly accelerated wound healing in mice compares to the control group (Figure 9D).

\section{Evaluation of side effects using DVDMS-PACT}

We examined the potential in vivo toxicity of DVDMSPACT. We harvested major organs: heart, liver, spleen, and kidney. We were not in a position to detect any organ damage using H\&E staining (Figure 10A). Furthermore, we did not detect any overt signs of toxic side effects or changes in body weight and organ weight (Figure 10B and C) with 

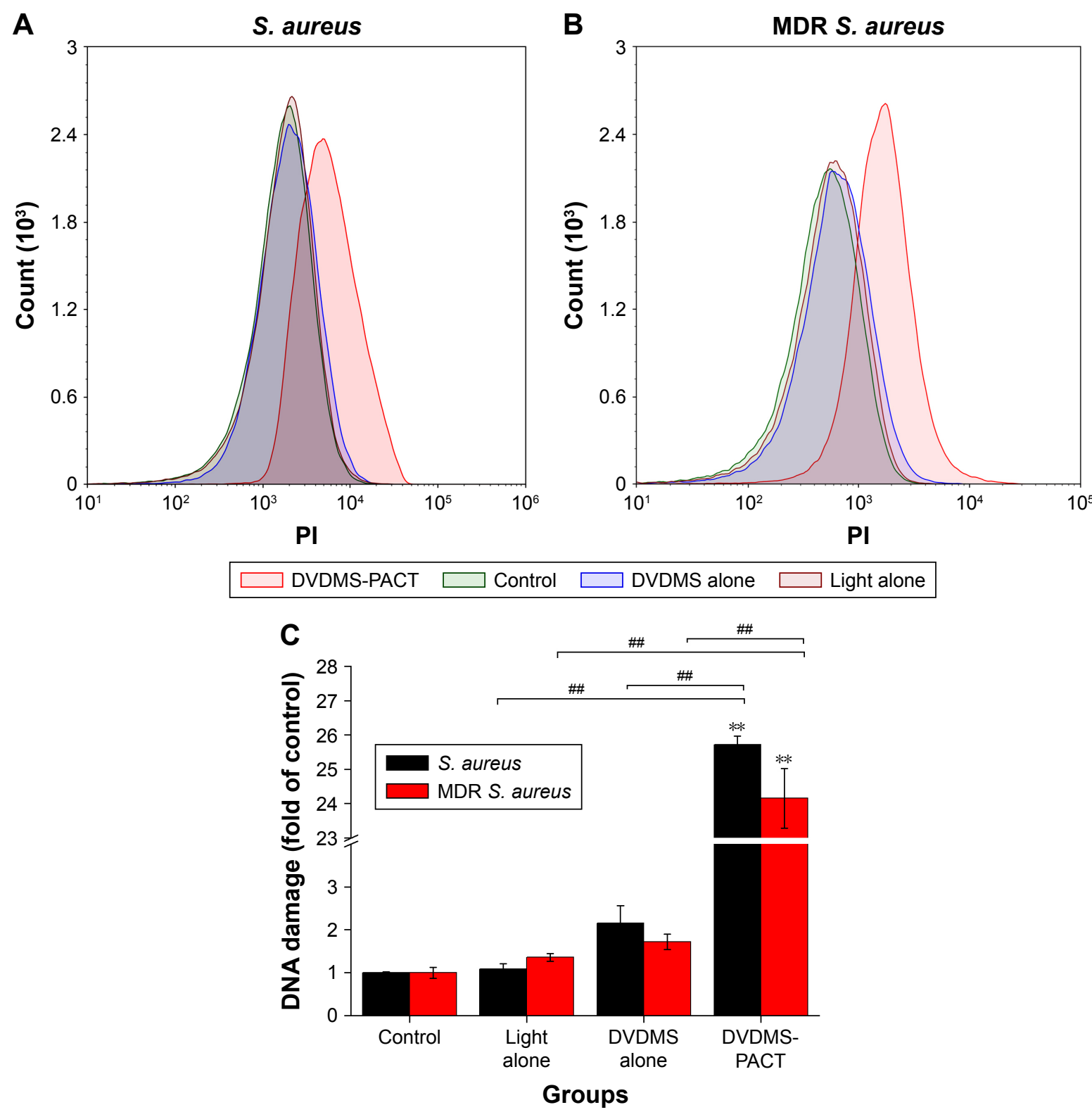

Figure 6 Effects on DNA fragmentation of Staphylococcus aureus.

Notes: Bacterial cells were treated with light alone, DVDMS alone, and PACT, then stained with PI and analyzed by flow cytometry. (A, B) DNA damage vs PI fluorescence. Data expressed as means $\pm S D$ of three independent experiments. $* * P<0.0$ I vs control; ${ }^{\#} P<0.01$ vs DVDM alone and light alone.

Abbreviations: DVDMS, sinoporphyrin sodium; MDR, multidrug-resistant; PACT, photodynamic antimicrobial chemotherapy; PI, propidium iodide.

DVDMS-PACT at $10 \mu \mathrm{M}$, suggesting that DVDMS had no adverse effect on the growth of mice. These results suggested there were no observable side effects of DVDMS at the treatment dose and that the treatment was relatively safe to administer. However, the present safety evaluation of DVDMS is somewhat limited, and should be expanded in a series of rigorous assessments before DVDMS is clinically used.

\section{Discussion}

Burns, a form of skin wound, are a frequently occurring affliction in the clinic. Bacterial infection, the main complication of burn patients, is the dominant cause of death. As such, antiinfection treatment is an important link for burn patients. ${ }^{37}$ In addition to this, the emergence of high antimicrobial resistance among bacterial pathogens has made management of treatment of postoperative wound infections difficult. ${ }^{38,39}$ However, MDR clinical pathogens cause dangerous, lifethreatening invasive infections and are resistant to a wide range of broad-spectrum antibiotics. The mechanisms behind multidrug (MD) resistance are complex. Based on the frequent development of MDR bacterial strains from the hospital environment, there is an urgent need for the development of 
A
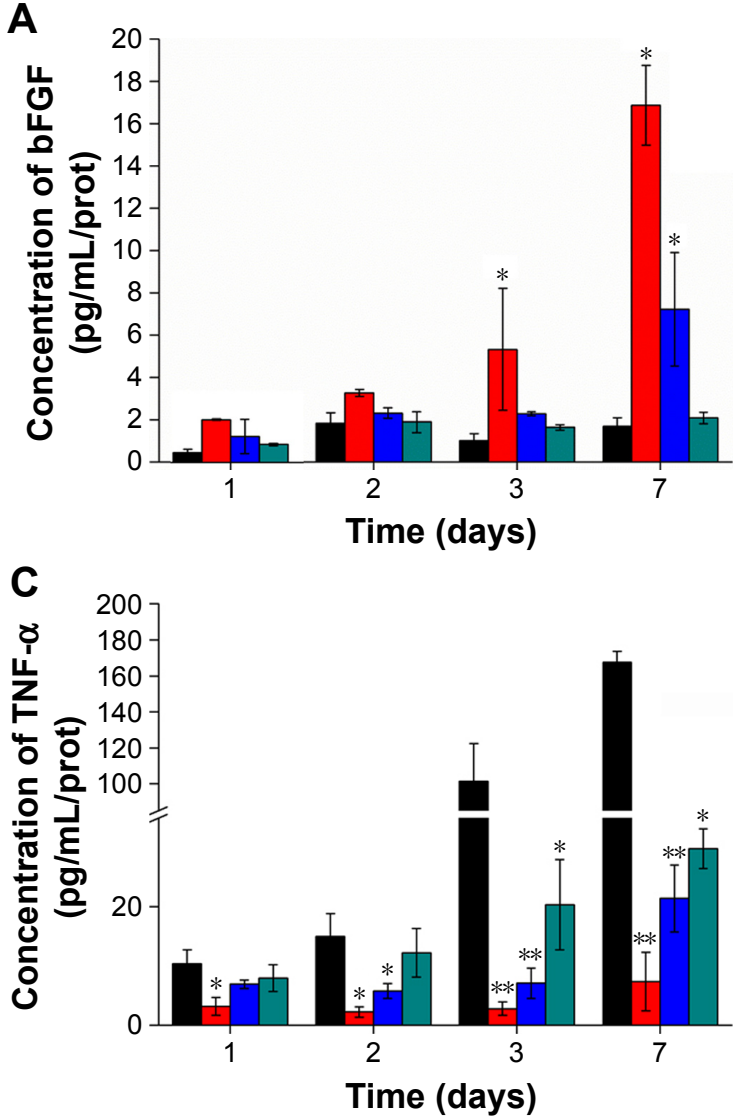

B

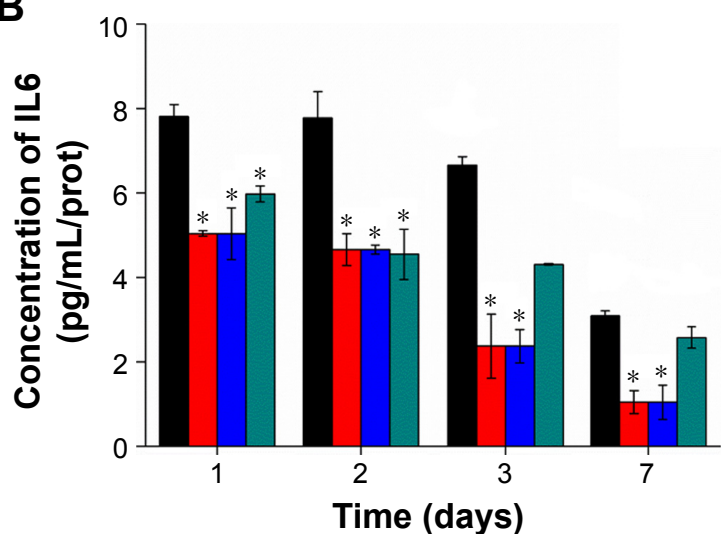

D

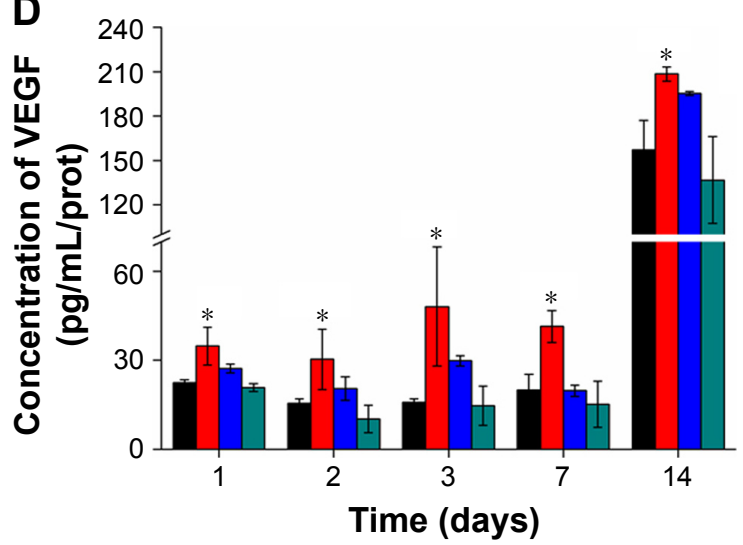

Model $\square 10 \mu \mathrm{M} \square 5 \mu \mathrm{M} \square 2 \mu \mathrm{M}$

Figure 7 Different factors determined by ELISA.

Notes: (A) bFGF levels were determined by ELISA in the four different groups at I, 2, 3, and 7 days following full-thickness injury of mice. (B) IL6 levels were determined by ELISA in the four different groups at I, 2, 3, and 7 days following full-thickness injury of rats. (C) TNF $\alpha$ levels were determined by ELISA in the four different groups at I, 2, 3, and 7 days following full-thickness injury of rats. (D) VEGF levels were determined by ELISA in the five different groups at I, 2, 3, 7, and I4 days following full-thickness injury of rats. $* P<0.05, * * P<0.01$. Data shown as means \pm SD from eight mice in each group.

Abbreviation: ELISA, enzyme-linked immunosorbent assay.

alternative medicines against MDR pathogens. ${ }^{40}$ The development of strategies to combat bacteria growing in antibiotics is a challenging task, given that those bacteria are much more resistant to antimicrobial therapies.

PACT is a promising therapeutic option to control microbial growth effectively. The photosensitizer (PS) is the critical component of PACT, and can directly affect efficiency. DVDMS is an identified sensitizer based on Photofrine ${ }^{\circledR}$ (PF). Research has shown that DVDMS is a good sensitizer of antibacterial activity in vitro and can produce a large amount of ROS. ${ }^{31}$ The clinical value of PACT as a topical antimicrobial treatment depends both on its bactericidal activity and its cytotoxicity toward host tissue. ${ }^{18}$

In this study, we demonstrated that it is possible to photoinactivate $S$. aureus rapidly when present in a burn infected with DVDMS as PS in vitro and in vivo. Fluorescence microscopy showed DVDMS concentration in bacteria reached its maximum in 75 minutes (Figure 2). We primarily investigated the bactericidal effect of PACT using DVDMS on $S$. aureus and MDR $S$. aureus. In our preliminary study, we found that DVDMS reached its maximum 75 minutes after incubation, and $50 \mathrm{~J} / \mathrm{cm}^{2}$ light with DVDMS had a significant effect on $S$. aureus. Firstly, we optimized DVDMSPACT parameters. A $4 \log _{10}$ reduction in CFU was observed at $5 \mu \mathrm{M}$ DVDMS combined with $50 \mathrm{~J} / \mathrm{cm}^{2}$ light. Moreover, the same results were achieved in MDR $S$. aureus. The CFU assay showed that DVDMS-PACT decreased the survival of bacteria in a DVDMS dose- and light dose-dependent manner (Figure 3).

It has been reported that ROS contribute to the microbicidal activity of phagocytes, regulation of signal transduction, and gene expression, and induce oxidative damage to nucleic acid, proteins, and lipids. ${ }^{25}$ Our previous study ${ }^{31}$ demonstrated ROS in PACT treatment in antibacterial action. Figure 4 

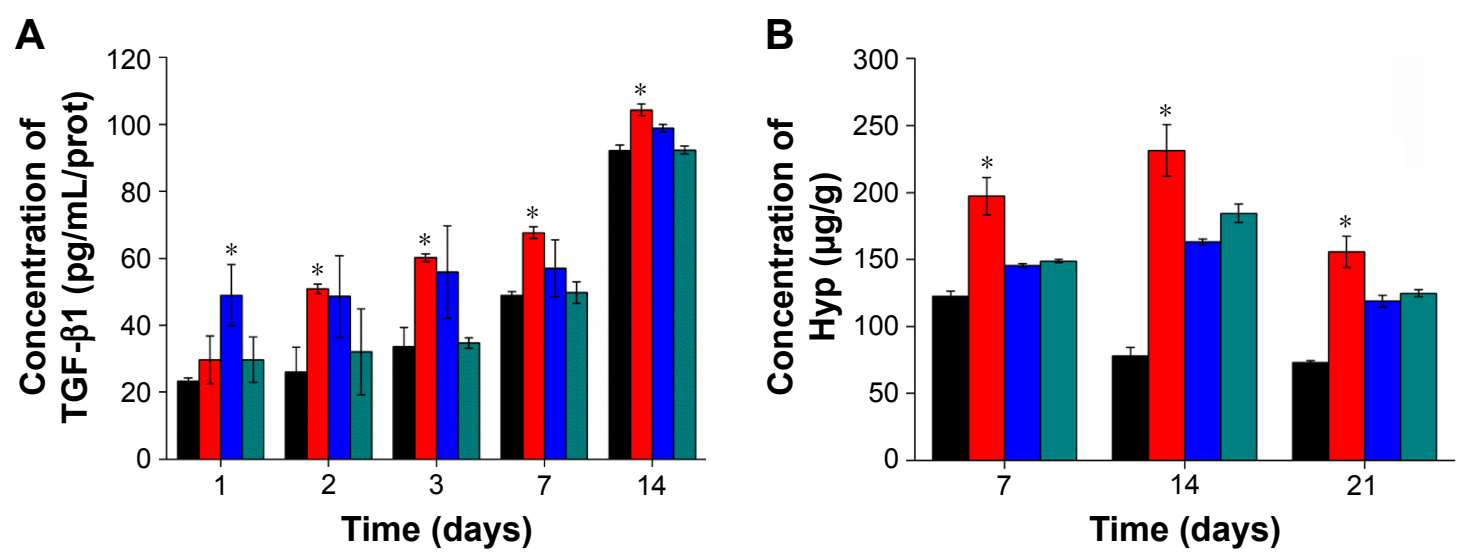

Model $10 \mu \mathrm{M}=5 \mu \mathrm{M}=2 \mu \mathrm{M}$

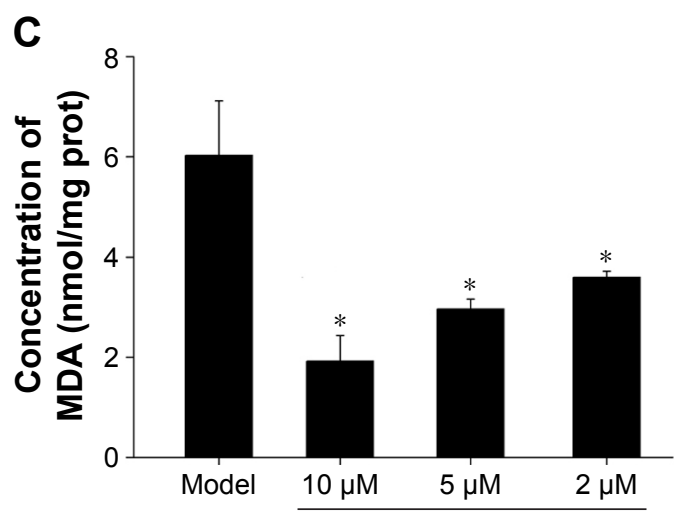

Light dose $\left(50 \mathrm{~J} / \mathrm{cm}^{2}\right)$

Figure 8 Factor levels of traumatic skin tissue at different times.

Notes: (A) TGF $\beta_{\text {I }}$ levels were determined by ELISA in the groups at I, 2, 3, 7, and I4 days following full-thickness injury of rats. (B) Hyp levels were tested in the groups at 7, 14, 21 days following full-thickness injury of rats. (C) MDA levels were tested in the groups at 14 days following full-thickness injury of rats. $* P<0.05$. Data shown as means \pm SD from eight mice in each group.

Abbreviations: ELISA, enzyme-linked immunosorbent assay; Hyp, hydroxyproline; MDA, malondialdehyde.

shows that abundant ROS were generated after PACT treatment. What is more, the amount of ROS produced occurred in a light dose-dependent manner (Figure 4C). ROS induce cell death through a variety of photochemical mechanisms.

There have been different opinions on the criteria for bacterial viability to define a bacterial cell as dead or alive..$^{41-44}$ Cellular and membrane integrity is considered to be one criterion distinguishing between viable and dead bacterial cells. Viable cells are assumed to have intact and tight cell membranes that cannot be penetrated by some staining compounds, whereas dead cells are considered to have disrupted and/or broken membranes. ${ }^{26,45}$ The combined usage of SYTO 9 and PI in a commercially available kit was first described in 1996, and it is promoted as a rapid and reliable method for assessment of bacterial viability that gives quantitative results and can be applied to microplate-reader flow-cytometry combined staining with SYTO 9 and PI.
Green fluorescent SYTO 9 is a cell membrane-permeable agent and red fluorescent PI is an impermeable reagent for nuclei staining. The fluorescent SYTO 9 binds only with viable bacterial cells, whereas the membrane-impermeable PI is commonly used to stain damaged or compromised cells and emits red fluorescence, which usually indicates dead cells. ${ }^{46}$ Fluorescence intensity was measured with flow cytometry and fluorescence microscopy. Data in Figure 5 show that membrane permeability was changed after PACT treatment and permeability enhanced with PACT dose increased. Furthermore, the presence of condensed chromatin and DNA fragmented in $S$. aureus/MDR $S$. aureus confirmed that DVDMS-PACT can induce DNA damage, which might prove crucial for the role of ROS in PACT treatment (Figure 6).

Despite continual advances in treatment of burns, wound infection still remains a huge threat to burn patients. Septic processes account for approximately $73 \%$ of all death within 

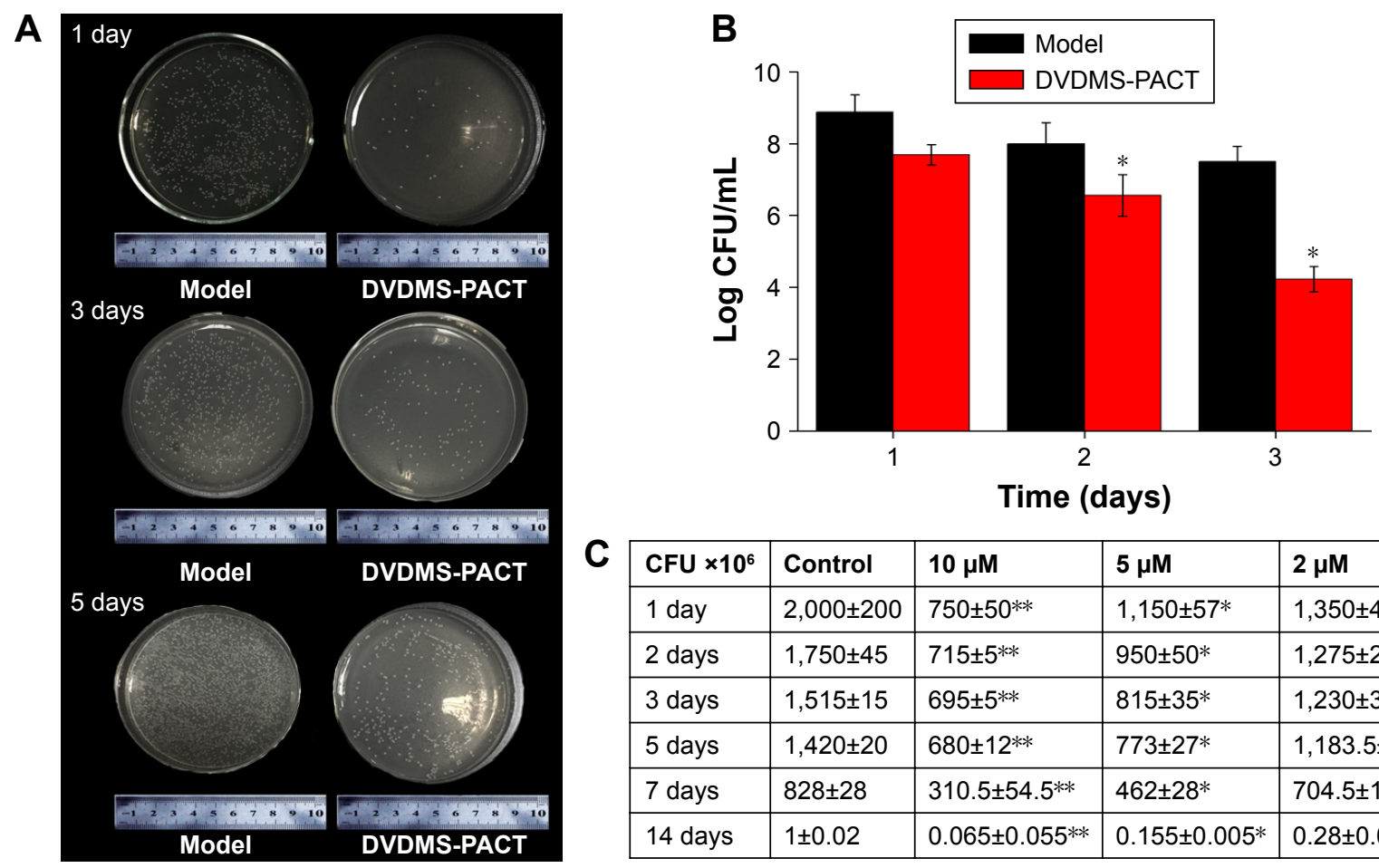

\begin{tabular}{|l|l|l|l|l|}
$\mathbf{C} \mathbf{C F U} \times \mathbf{1 0 ^ { 6 }}$ & Control & $\mathbf{1 0} \boldsymbol{\mu \mathbf { M }}$ & $\mathbf{5} \boldsymbol{\mu M}$ & $\mathbf{2} \boldsymbol{\mu M}$ \\
\hline 1 day & $2,000 \pm 200$ & $750 \pm 50^{* *}$ & $1,150 \pm 57^{*}$ & $1,350 \pm 48$ \\
\hline 2 days & $1,750 \pm 45$ & $715 \pm 5^{* *}$ & $950 \pm 50^{*}$ & $1,275 \pm 25$ \\
\hline 3 days & $1,515 \pm 15$ & $695 \pm 5^{* *}$ & $815 \pm 35^{*}$ & $1,230 \pm 30$ \\
\hline 5 days & $1,420 \pm 20$ & $680 \pm 12^{* *}$ & $773 \pm 27^{*}$ & $1,183.5 \pm 16.5$ \\
\hline 7 days & $828 \pm 28$ & $310.5 \pm 54.5^{* *}$ & $462 \pm 28^{*}$ & $704.5 \pm 10.5$ \\
\hline 14 days & $1 \pm 0.02$ & $0.065 \pm 0.055^{* *}$ & $0.155 \pm 0.005^{*}$ & $0.28 \pm 0.04$ \\
\hline
\end{tabular}

D

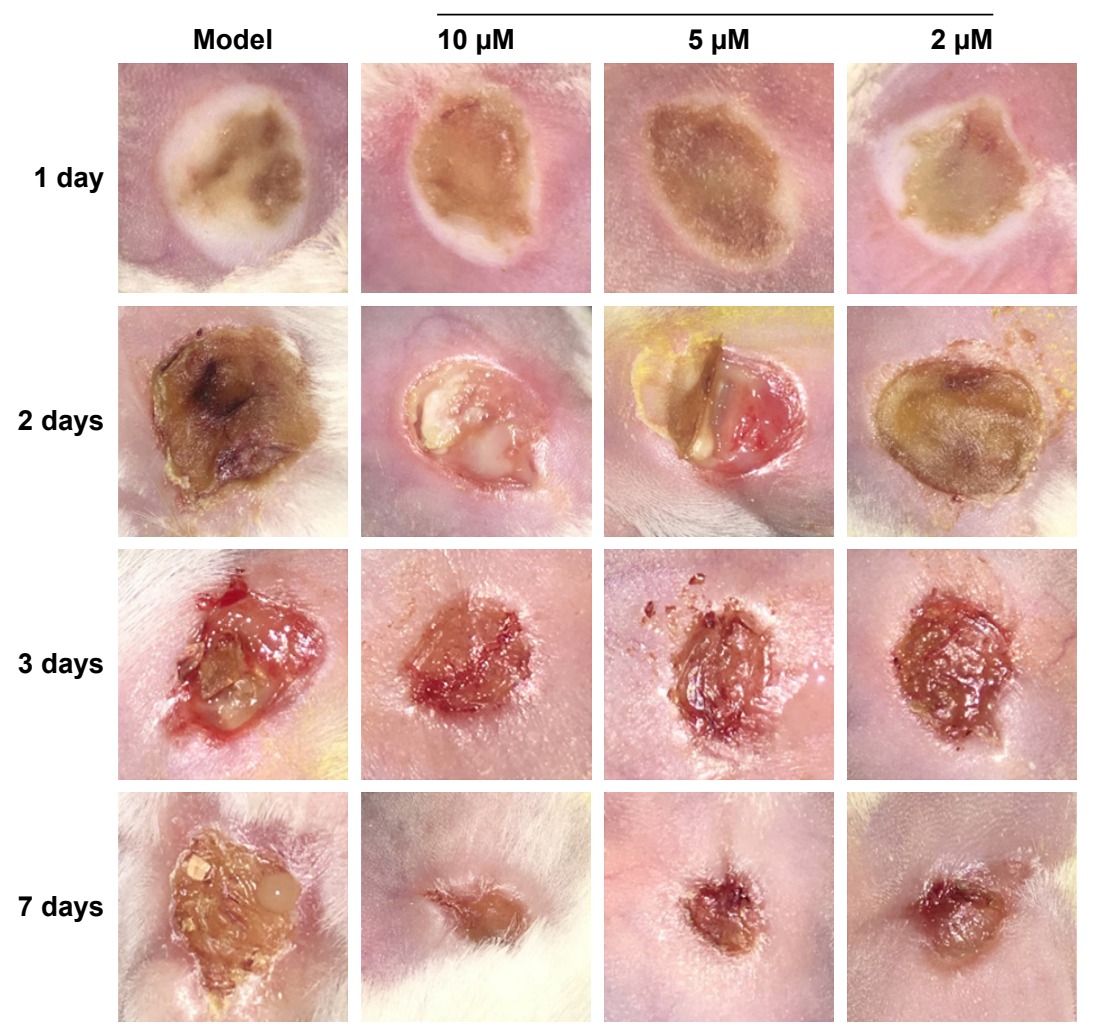

Figure 9 CFU assay of Staphylococcus aureus and MDR S. aureus of skin tissue at different times.

Notes: (A) Representative bacterial colonies on trypticase soy agar are shown. (B) MDR S. aureus CFU counts in PACT treatment and the model group (without any treatment) were assessed with $20 \mu \mathrm{M}$ DVDMS at different times. (C) Bacteria counts of $S$. aureus with $10 \mu M$ DVDMS treatment at different times. Data expressed as means $\pm S D$ of three independent experiments. $* P<0.05$; $* P<<0.0$ I. (D) Wound observation at different times after PACT treatment.

Abbreviations: DVDMS, sinoporphyrin sodium; MDR, multidrug-resistant; PACT, photodynamic antimicrobial chemotherapy. 
A

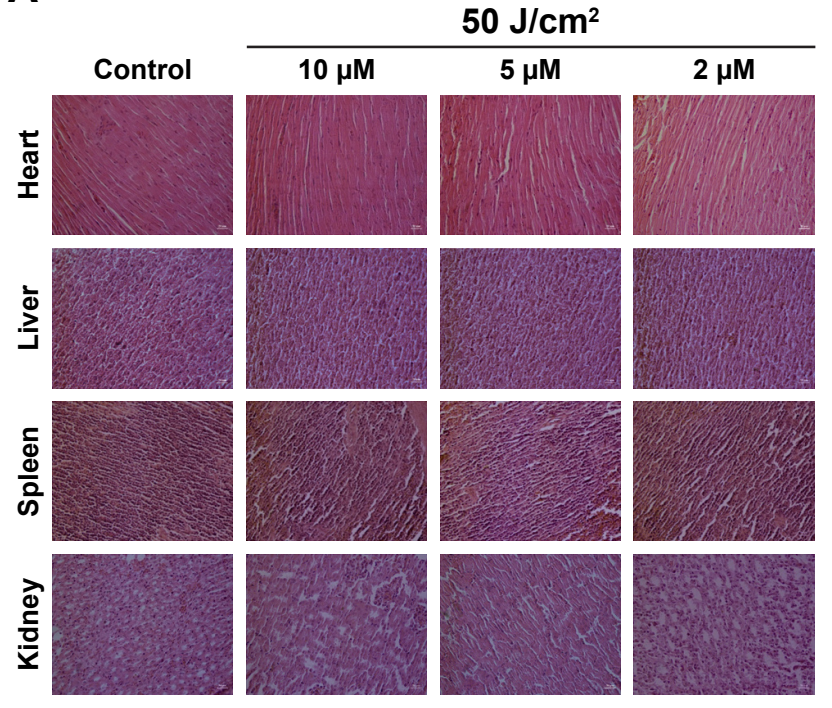

B

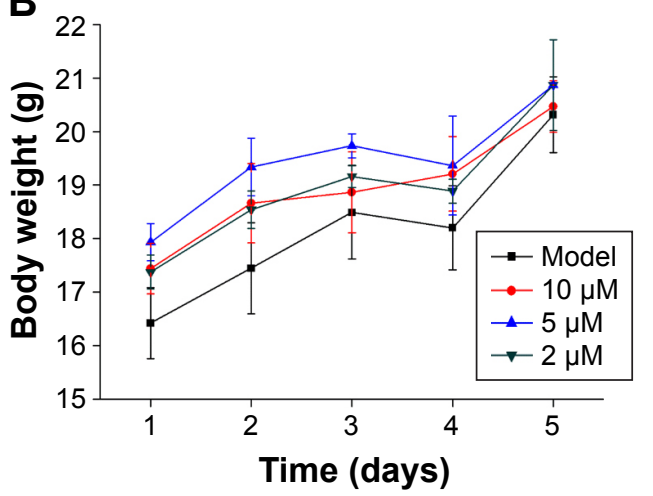

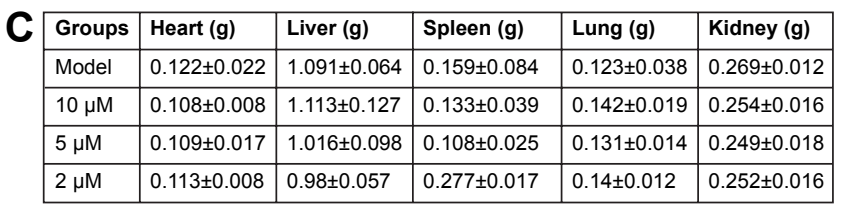

Figure 10 Evaluation of side effects using DVDMS-PACT.

Notes: (A) Effect of different treatments on structural changes in major organs in mice. Major organ sections were stained with H\&E. Histopathological changes were observed under light microscopy. (B) Body weight versus number of days after different treatments. (C) Weight of major organs in the mice. Data shown as means \pm SD from eight mice in each group.

Abbreviations: DVDMS, sinoporphyrin sodium; PACT, photodynamic antimicrobial chemotherapy.

the initial 5 days of a burn. ${ }^{44,47}$ The presence of large amounts of necrotic tissue with protein-rich wound exudates at the burn site provides a highly nutritive medium for the proliferation of microbes, leading to increased rates of wound infection in these patients. ${ }^{48,49}$ In this study, we demonstrated that it is possible to photoinactivate $S$. aureus rapidly when it is present in a burn wound with DVDMS as PS. The fact that the bacteria had 48 hours to colonize the wound and multiply manyfold gives the experiments more clinical significance than if PACT was carried out shortly after bacterial contamination. The use of CFU counts from homogenized tissues removed from euthanized animals allows the progress of the infection to be followed over time in individual mice (Figure 9). The necessity of using a much higher concentration of DVDMS in vivo (10 $\mu \mathrm{M}$ in burn wounds compared to $5 \mu \mathrm{M}$ that efficiently killed bacteria in vitro) may be explained by the much higher concentration of biological material in the infected burn (host proteins and cells, in addition to bacteria) to which the PS can bind. MDR S. aureus bacteria is consistent with the results, and the concentration of the whole is greater than normal bacteria cause the drugresistant bacteria itself to have a corresponding mechanism of drug resistance, such as efflux pump, the photosensitive is restricted to entrance, and the specific mechanisms needs to be further confirmed. This means that the vast majority of the singlet oxygen produced in the burn infection is wasted on nonbacterial matter, and it is thus necessary to produce much more singlet oxygen to achieve bacterial cell killing. Therefore, in order to optimize PACT in burn infections, selectivity of the PS for the bacteria over mammalian cells and proteins is vital. In addition, Figure $8 \mathrm{D}$ shows that mouse skin healed faster in the PACT-treatment group.

At infection sites, the release and accumulation of bacterial components, such as lipoteichoic acid, from Gram-positive bacteria are known to trigger various inflammatory mediators. ${ }^{50}$ The experiment confirmed that PACT can significantly reduce the number of bacteria colonies under phase callus, increase the rate of wound healing, and promote resistance to infection and healing efficacy. In specific conditions of inflammation-mediated pathophysiology, TNF $\alpha$ is recognized as a crucial contributing factor. ${ }^{51,52}$ Impaired healing in animal models and age-related delayed healing of acute human wounds exhibit raised local and systemic levels of TNF $\alpha$ that may parallel the proinflammatory phenotype. ${ }^{53,54}$ The pleiotropic cytokine IL6 is produced by macrophages, dendritic cells, mast cells, and other innate immune cells; consequently, this cytokine has long been considered a marker of inflammation. ${ }^{55}$ Using ELISA to detect the concentration of TNF $\alpha$ and IL6 at different times, results showed that PACT treatment inhibited inflammation-factor secretion, significantly reduce the scalded-tissue concentration of TNF $\alpha$ and IL6, and prevent further deepening of the wound. bFGF mediates angiogenic activity in early surgical wounds, and significantly accelerates granular tissue formation and reepithelialization. ${ }^{56}$ TGF $\beta_{1}$ plays an important role in the process of differentiation 
and tissue formation, can regulate cell proliferation, differentiation, and mesenchymal cell protein expression, and participates in the epithelial regeneration in the process of wound healing, fibroblast fibrosis, interstitial proliferation, angiogenesis, and the important stimulating factor of granulation-tissue fibrosis. ${ }^{57,58}$ Results showed that in the healing process, PACT-treatment groups induced higher expression $\mathrm{bFGF}$ and TGF $\beta_{1}$ than the model control group. These results suggest that PACT treatment can inhibit wound deterioration and reduce inflammation. In addition, the concentration of VEGF rose almost at the same time in the PACT-treatment process. VEGF has been described as one of the most important stimulators of angiogenesis and vasopermeability, and is produced by macrophages as a result of the burn's hypoxic environment to stimulate endothelial cell migration and proliferation. ${ }^{41,42}$ Indeed, this increase in VEGF levels coincided with the decrease in wound area, suggesting the importance of angiogenesis stimulation by DVDMS-PACT to the overall acceleration of wound healing, observed mainly at 7 and 14 days (Figure 7). MDA levels showed us the extent of cell damage caused by free radicals. ${ }^{59}$ Collagen not only confers strength and integrity to the tissue matrix but also plays an important role in homeostasis and epithelialization in wound healing. Collagen is composed of the amino acid Hyp, which has been used as a biochemical marker for tissue collagen. ${ }^{60}$ MDA and Hyp levels demonstrated the promotion of wound healing after PACT treatment.

Finally, there were no detectable side effects using DVDMS-PACT at the therapeutic dose according to preliminary safety analysis, and the treatment was relatively safe to administer. Nanomaterials are used for antibacterial purposes, due to their unique advantages. Smaller particles facilitate penetration and enhance their antibacterial properties, higher entrapment efficiency of nanoparticles increases drug content at the site of action, and lower minimum inhibitory concentration and minimum bactericidal concentration achieved with nanoparticles indicates that better antibacterial activity is achieved with smaller amounts of drug. Further work is necessary on modification and loading of DVDMS to enhance PACT antibacterial efficiency.

\section{Conclusion}

Taken together, our results clearly demonstrate the advantages of DVDMS compared to other clinical sensitizers, as well as a synergistic effect between DVDMS and light. DVDMSPACT can effectively suppress bacteria and MDR-bacteria proliferation, and produces a large amount of ROS to damage bacterial cell membranes. In addition, DVDMS-PACT can promote the healing of wounds in burn infection.

\section{Acknowledgments}

This research was supported by the National Natural Science Foundation of China (81472846 and 81571834), Natural Science Foundation of Shaanxi Province (2017JM8004), and Fundamental Research Funds for Central Universities (GK201602003 and 2017CBY006).

\section{Disclosure}

The authors report no conflicts of interest in this work.

\section{References}

1. Priya KS, Gnanamani A, Radhakrishnan N, Babu M. Healing potential of Datura alba on burn wounds in albino rats. $J$ Ethnopharmacol. 2002;83(3):193-199.

2. Upadhyay N, Kumar R, Mandotra S, et al. Safety and healing efficacy of sea buckthorn (Hippophae rhamnoides L.) seed oil on burn wounds in rats. Food Chem Toxicol. 2009;47(6):1146-1153.

3. Sen CK, Gordillo GM, Roy S, et al. Human skin wounds: a major and snowballing threat to public health and the economy. Wound Repair Regen. 2009;17(6):763-771.

4. Allison RR, Moghissi K. Photodynamic therapy (PDT): PDT mechanisms. Clin Endosc. 2013;46(1):24-29.

5. Seil JT, Webster TJ. Antimicrobial applications of nanotechnology: methods and literature. Int J Nanomedicine. 2012;7:2767-2781.

6. Khorasani G, Hosseinimehr SJ, Zamani P, Ghasemi M, Ahmadi A. The effect of saffron (Crocus sativus) extract for healing of second-degree burn wounds in rats. Keio J Med. 2008;57(4):190-195.

7. Chaby G, Senet P, Vaneau M, et al. Dressings for acute and chronic wounds: a systematic review. Arch Dermatol. 2007;143(10):1297-1304.

8. Wang $\mathrm{F}$, Gao W, Thamphiwatana $\mathrm{S}$, et al. Hydrogel retaining toxin-absorbing nanosponges for local treatment of methicillinresistant Staphylococcus aureus infection. Adv Mater. 2015;27(22): 3437-3443.

9. Müller P, Alber DG, Turnbull L, et al. Synergism between Medihoney and rifampicin against methicillin-resistant Staphylococcus aureus (MRSA). PLoS One. 2013;8(2):e57679.

10. Wu G, Zhu B, Hong X, Luo P, Xia Z. Role of cytokines in host defense against Staphylococcus aureus skin infection. Histol Histopathol. 2017;32(8):761-766.

11. Greenhalgh DG. Topical antimicrobial agents for burn wounds. Clin Plast Surg. 2009;36(4):597-606.

12. Praphakar RA, Munusamy MA, Sadasivuni KK, Rajan M. Targeted delivery of rifampicin to tuberculosis-infected macrophages: design, in-vitro, and in-vivo performance of rifampicin-loaded poly(ester amide)s nanocarriers. Int J Pharm. 2016;513(1-2):628-635.

13. Rice LB. Mechanisms of resistance and clinical relevance of resistance to $\beta$-lactams, glycopeptides, and fluoroquinolones. Mayo Clinic Proc. 2012;87(2):198-208.

14. Klahn P, Brönstrup M. Bifunctional antimicrobial conjugates and hybrid antimicrobials. Nat Prod Rep. 2017;34(7):832-885.

15. Mousavi M, Behrouz B, Irajian G, Mahdavi M, Korpi F, Motamedifar M. Passive immunization against Pseudomonas aeruginosa recombinant PilA in a murine burn wound model. Microb Pathog. 2016;101:83-88.

16. Fair RJ, Tor Y. Antibiotics and bacterial resistance in the 21st century. Perspect Med Chem. 2014;6:25-64.

17. Dudhagara PR, Ghelani AD, Patel RK. Phenotypic characterization and antibiotics combination approach to control the methicillin-resistant Staphylococcus aureus (MRSA) strains isolated from the hospital derived fomites. Asian J Med Sci. 2014;2(2):72-78.

18. Lambrechts SA, Demidova TN, Aalders MC, Hasan T, Hamblin MR. Photodynamic therapy for Staphylococcus aureus infected burn wounds in mice. Photochem Photobiol Sci. 2005;4(7):503-509. 
19. Beyth N, Houri-Haddad Y, Domb A, Khan W, Hazan R. Alternative antimicrobial approach: nano-antimicrobial materials. Evid Based Complement Alternat Med. 2015;2015:246012.

20. Liu HL, Dai SH, Fu KY, Hsu SH. Antibacterial properties of silver nanoparticles in three different sizes and their nanocomposites with a new waterborne polyurethane. Int J Nanomedicine. 2010;5:1017-1028.

21. Hu G, Xiao L, Tong P, et al. Antibacterial hemostatic dressings with nanoporous bioglass containing silver. Int J Nanomedicine. 2012;7: 2613-2620.

22. Cheng Y, Wu J, Gao B, et al. Fabrication and in vitro release behavior of a novel antibacterial coating containing halogenated furanone-loaded poly(L-lactic acid) nanoparticles on microarc-oxidized titanium. Int $J$ Nanomedicine. 2012;7:5641-5652.

23. Saravanan M, Nanda A. Extracellular synthesis of silver bionanoparticles from Aspergillus clavatus and its antimicrobial activity against MRSA and MRSE. Colloids Surf B Biointerfaces. 2010;77(2):214-218.

24. Saravanan M, Vemu AK, Barik SK. Rapid biosynthesis of silver nanoparticles from Bacillus megaterium (NCIM 2326) and their antibacterial activity on multi drug resistant clinical pathogens. Colloids Surf B Biointerfaces. 2011;88(1):325-331.

25. Pan JS, Hong MZ, Ren JL. Reactive oxygen species: a double-edged sword in oncogenesis. World J Gastroenterol. 2009;15(14):1702-1707.

26. Stiefel P, Schmidt-Emrich S, Maniura-Weber K, Ren Q. Critical aspects of using bacterial cell viability assays with the fluorophores SYTO9 and propidium iodide. BMC Microbiol. 2015;15:36.

27. Sperandio FF, Huang YY, Hamblin MR. Antimicrobial photodynamic therapy to kill Gram-negative bacteria. Recent Pat Antiinfect Drug Discov. 2013;8(2):108-120.

28. Wainwright M. Photodynamic antimicrobial chemotherapy (PACT). $J$ Antimicrob Chemother. 1998;42(1):13-28.

29. Zolfaghari PS, Packer S, Singer M, et al. In vivo killing of Staphylococcus aureus using a light-activated antimicrobial agent. BMC Microbiol. 2009;9:27.

30. Zeina B, Greenman J, Purcell W, Das B. Killing of cutaneous microbial species by photodynamic therapy. Br J Dermatol. 2001;144(2): 274-278.

31. Mai B, Wang X, Liu Q, et al. The antibacterial effect of sinoporphyrin sodium photodynamic therapy on Staphylococcus aureus planktonic and biofilm cultures. Lasers Surg Med. 2016;48(4):400-408.

32. Krysko DV, Vanden BT, D'Herde K, Vandenabeele P. Apoptosis and necrosis: detection, discrimination and phagocytosis. Methods. 2008; 44(3):205-221.

33. Fan J, Wang Y, Wang X, et al. The antitumor activity of Meconopsis horridula Hook, a traditional Tibetan medical plant, in murine leukemia L1210 cells. Cell Physiol Biochem. 2015;37(3):1055-1065.

34. Gilpin DA. Calculation of a new Meeh constant and experimental determination of burn size. Burns. 1996;22(8):607-611.

35. Zhang Y, Liang D, Dong L, et al. Anti-inflammatory effects of novel curcumin analogs in experimental acute lung injury. Respir Res. 2015; 16:43.

36. Pakyari M, Farrokhi A, Maharlooei MK, Ghahary A. Critical role of transforming growth factor beta in different phases of wound healing. Adv Wound Care (New Rochelle). 2013;2(5):215-224.

37. Olson MM, Lee JT. Continuous, 10-year wound infection surveillance: results, advantages, and unanswered questions. Arch Surg. 1990;125(6): 794-803.

38. Andhoga J, Macharia AG, Maikuma IR, Wanyonyi ZS, Ayumba BR, Kakai R. Aerobic pathogenic bacteria in post-operative wounds at Moi Teaching and Referral Hospital. East Afr Med J. 2002;79(12): 640-644.

39. Nanda A, Saravanan M. Biosynthesis of silver nanoparticles from Staphylococcus aureus and its antimicrobial activity against MRSA and MRSE. Nanomedicine. 2009;5(4):452-456.

40. Kasithevar M, Periakaruppan P, Muthupandian S, Mohan M. Antibacterial efficacy of silver nanoparticles against multi-drug resistant clinical isolates from post-surgical wound infections. Microb Pathog. 2017; 107:327-334.
41. Kim CK, Karau MJ, Greenwood-Quaintance KE, et al. Superantigenproducing Staphylococcus aureus elicits systemic immune activation in a murine wound colonization model. Toxins (Basel). 2015;7(12): 5308-5319.

42. Klevens RM, Morrison MA, Nadle J, et al. Invasive methicillinresistant Staphylococcus aureus infections in the United States. JAMA. 2007;298(15):1763-1771

43. Li X, Guo H, Tian Q, et al. Effects of 5-aminolevulinic acid-mediated photodynamic therapy on antibiotic-resistant staphylococcal biofilm: an in vitro study. $J$ Surg Res. 2013;184(2):1013-1021.

44. Li L, Liu Y, Hao P, et al. PEDOT nanocomposites mediated dual-modal photodynamic and photothermal targeted sterilization in both NIR I and II window. Biomaterials. 2015;41:132-140.

45. Gopinath V, Priyadarshini S, Loke MF, et al. Biogenic synthesis, characterization of antibacterial silver nanoparticles and its cell cytotoxicity. Arab J Chem. Epub 2015 Dec 10.

46. Gopinath V, Priyadarshini S, Al-Maleki AR, et al. In vitro toxicity, apoptosis and antimicrobial effects of phyto-mediated copper oxide nanoparticles. RSC Adv. 2016;6(112):110986-110995.

47. Dou JL, Jiang YW, Xie JQ, Zhang XG. New is old, and old is new: recent advances in antibiotic-based, antibiotic-free and ethnomedical treatments against methicillin-resistant Staphylococcus aureus wound infections. Int J Mol Sci. 2016;17(5):E617.

48. Ventola CL. The antibiotic resistance crisis: part 1: causes and threats. P T. 2015;40(4):277-283.

49. Bowler PG, Duerden BI, Armstrong DG. Wound microbiology and associated approaches to wound management. Clin Microbiol Rev. 2001; 14(2):244-269.

50. Song XY, Zeng L, Jin WW, et al. Secretory leukocyte protease inhibitor suppresses the inflammation and joint damage of bacterial cell wallinduced arthritis. $J$ Exp Med. 1999;190(4):535-542.

51. Ashcroft GS, Jeong MJ, Ashworth JJ, et al. Tumor necrosis factor-alpha (TNF- $\alpha$ ) is a therapeutic target for impaired cutaneous wound healing. Wound Repair Regen. 2012;20(1):38-49.

52. Brüünsgaard H, Pedersen BK. Age-related inflammatory cytokines and disease. Immunol Allergy Clin North Am. 2003;23(1):15-39.

53. Bruunsgaard $\mathrm{H}$. Effects of tumor necrosis factor-alpha and interleukin-6 in elderly populations. Eur Cytokine Netw. 2002;13(4):389-391.

54. Wang J, Wang Q, Han T, et al. Soluble interleukin-6 receptor is elevated during influenza A virus infection and mediates the IL- 6 and IL-32 inflammatory cytokine burst. Cell Mol Immunol. 2015;12(5): 633-644.

55. Nissen NN, Polverini PJ, Gamelli RL, Dipietro LA. Basic fibroblast growth factor mediates angiogenic activity in early surgical wounds. Surgery. 1996;119(4):457-465.

56. Herrera BS, Kantarci A, Zarrough A, Hasturk H, Leung KP, Van Dyke TE. LXA4 actions direct fibroblast function and wound closure. Biochem Biophys Res Commun. 2015;464(4):1072-1077.

57. Ferguson MWJ, O'Kane S. Scar-free healing: from embryonic mechanisms to adult therapeutic intervention. Philos Trans $R$ Soc Lond $B$ Biol Sci. 2004;359(1445):839-850.

58. Honnegowda TM, Udupa EG, Rao P, Kumar P, Singh R. Superficial burn wound healing with intermittent negative pressure wound therapy under limited access and conventional dressings. World J Plast Surg. 2016;5(3):265-273.

59. Ghaffari A, Manafi A, Moghimi HR. Clindamycin phosphate absorption from nanoliposomal formulations through third-degree burn eschar. World J Plast Surg. 2015;4(2):145-152.

60. Kashi TS, Eskandarion S, Esfandyari-Manesh M, et al. Improved drug loading and antibacterial activity of minocycline-loaded PLGA nanoparticles prepared by solid/oil/water ion pairing method. Int $J$ Nanomedicine. 2012;7:221-234. 
International Journal of Nanomedicine

Dovepress

\section{Publish your work in this journal}

The International Journal of Nanomedicine is an international, peerreviewed journal focusing on the application of nanotechnology in diagnostics, therapeutics, and drug delivery systems throughou the biomedical field. This journal is indexed on PubMed Central, MedLine, CAS, SciSearch ${ }^{\circledR}$, Current Contents ${ }^{\circledR} /$ Clinical Medicine,
Journal Citation Reports/Science Edition, EMBase, Scopus and the Elsevier Bibliographic databases. The manuscript management system is completely online and includes a very quick and fair peer-review system, which is all easy to use. Visit http://www.dovepress.com/ testimonials.php to read real quotes from published authors.

Submit your manuscript here: http://www.dovepress.com/international-journal-of-nanomedicine-journal 